\title{
Inspiring cognitive inference in a cortical network during REM sleep
}

\section{AUTHORS}

Kareem Abdou ${ }^{1,2,3,4}$, Kiriko Choko ${ }^{1,2,3}$, Mohamed H. Aly ${ }^{1,2,3,5}$, Reiko Okubo-Suzuki ${ }^{1,2,3}$, Shin-ichi Muramatsu ${ }^{6,7}$, Kaoru Inokuchi ${ }^{1,2,3,8^{*}}$

\section{AFFILIATIONS}

${ }^{1}$ Research Centre for Idling Brain Science, University of Toyama, Toyama, 930-0194, Japan

${ }^{2}$ Department of Biochemistry, Graduate School of Medicine and Pharmaceutical Sciences, University of Toyama, Toyama, Japan

${ }^{3}$ CREST, Japan Science and Technology Agency (JST), University of Toyama, Toyama, Japan

${ }^{4}$ Department of Biochemistry, Faculty of Pharmacy, Cairo University, Cairo 11562, Egypt.

${ }^{5}$ Pharmacology Department, Faculty of Pharmacy, The British University in Egypt, Cairo 11837, Egypt

${ }^{6}$ Division of Neurological Gene Therapy, Centre for Open Innovation, Jichi Medical University, Tochigi 3290498, Japan

${ }^{7}$ Centre for Gene and Cell Therapy, The Institute of Medical Science, The University of Tokyo, Tokyo 1088639, Japan

${ }^{8}$ Lead contact.

*Correspondence: inokuchi@med.u-toyama.ac.jp 


\section{SUMMARY}

Sleep has been proposed to facilitate inference, insight, and innovative problem-solving. However, it remains unclear how and when the subconscious brain can create novel ideas. Here, we show that cortical offline, but not online, activity is essential for inference evolution and that activity during rapid-eye movement (REM) sleep is sufficient to inspire inference from inadequate knowledge. In a transitive inference paradigm, mice gained the inference one day, but not shortly, after complete training. Inhibiting the neuronal computations in the anterior cingulate cortex (ACC) during post-learning sleep, but not during wakefulness, disrupted the inference without affecting the original memories. Furthermore, after insufficient learning, artificial activation of medial entorhinal cortex-ACC dialogue during only REM sleep created inferential knowledge. These findings establish causal evidence for the necessity and sufficiency of REM sleep in reorganizing existing knowledge to achieve novel inference, thereby highlighting the power of the idling brain in creativity and cognitive flexibility.

\section{KEYWORDS}

Inference, REM sleep, Idling brain, Medial prefrontal cortex, Offline activity, Creativity, Knowledge, Cognitive flexibility 


\section{INTRODUCTION}

Cognitive flexibility is a distinctive feature that is required for higher learning (Behrens et al., 2018). Inference is the process of drawing conclusions on the basis of evidence and reasoning. Inferential reasoning is a prominent property of cognitive flexibility since it relies on flexible and systematic organization of existing knowledge (Behrens et al., 2018; Ellenbogen et al., 2007). Inferential reasoning has been modeled in previous studies in humans, primates, and rodents using a transitive inference task, sensory pre-conditioning task, and spatial navigation task (Barron et al., 2020; Behrens et al., 2018; Dusek and Eichenbaum, 1997; Ellenbogen et al., 2007). Activation patterns of neurons in the medial prefrontal cortex (mPFC) have been suggested to represent inferential reasoning (Brunamonti et al., 2016; Spalding et al., 2018). However, circuit and temporal mechanisms of inference emergence are still unknown.

The ability to flexibly reorganize previously acquired knowledge allows for the emergence of novel ideas (Dusek and Eichenbaum, 1997; Ellenbogen et al., 2007; Wagner et al., 2004). Generalized abstracted knowledge can be developed during learning and persists throughout subsequent rest periods (Liu et al., 2019; Chen and Wilson, 2017; Lewis et al., 2018; Penagos et al., 2017; Stickgold and Walker, 2013); this occurs through online integration of past information with current related experiences (Barron et al., 2013; Wong et al., 2019) while keeping the identity of each experience unique (Abdou et al., 2018; Yokose et al., 2017). Experience-related neural representations are re-expressed during post-learning awake rest and sleep periods (Ghandour et al., 2019; Wilson and McNaughton, 1994). This neural replay has been proposed to consolidate memories (Boyce et al., 2016; Ghandour et al., 2019; Girardeau et al., 2009; Gridchyn et al., 2020). Previous work has found that awake replay events that occur during a spatial task not only represent recent experiences, but also novel spatial paths that might be confronted, which indicates that a whole spatial map has been formed (Gupta et al., 2010; Olafsdottir et al., 2015; Olafsdottir et al., 2018). Targeted reactivation of an implicitly 
learned sequence memory during sleep enables the development of explicit awareness of that sequence (Cousins et al., 2014). Previous reports have shown an offline improvement in a word-pair association task following sleep (Gais and Born, 2004; Plihal and Born, 1997; Plihal and Born, 1999; Walker, 2009). Enhanced cognitive performance has been linked with offline activity during non-rapid eye movement (NREM) (Wamsley et al., 2010) and rapid eye movement (REM) (Cai et al., 2009) sleep, but the most pertinent sleep stage and the circuits involved are still unclear. REM and NREM sleep have unique neurophysiological processes that impact cognition (Poe et al., 2010). REM sleep is characterized by ponto-geniculooccipital waves, theta rhythm, high acetylcholine levels, and upregulation of plasticity-related genes (Lewis et al., 2018). Long-term potentiation is easily induced during REM sleep (Bramham and Srebro, 1989). NREM sleep is characterized by regular occurrence of slow wave delta activity, high protein synthesis levels, and a rise in depotentiation-related genes and drop in long-term potentiation-related genes (Basheer et al., 1997; Cirelli and Tononi, 2000b; Cirelli and Tononi, 2000a; Poe et al., 2010; Pompeiano et al., 1995; Pompeiano et al., 1997; Pompeiano et al., 1994). Therefore, sleep stages differentially affect neuronal functions and may therefore modify cognitive capabilities.

The aforementioned studies (Cai et al., 2009; Cousins et al., 2014; Gupta et al., 2010; Olafsdottir et al., 2015; Olafsdottir et al., 2018; Wamsley et al., 2010) highlight the involvement of online and offline brain activity in cognitive flexibility. However, it remains unclear how and when the offline brain restructures information across chronologically separated, yet overlapping, experiences to extract novel inferential knowledge that was not created online.

\section{RESULTS}

\section{Randomizing existing knowledge is necessary for the emergence of inferential behavior}


We developed a transitive inference paradigm in mice that assesses the ability to infer new information that was not learned before, based on previous knowledge of overlapping memories. First, food-restricted mice were allowed to explore and habituate to an arena consisting of five different contexts (Context A, B, C, D, and E). These contexts were different in terms of geometry and/or floor texture and/or wall color and pattern. During the habituation period, mice did not show a significant innate preference to any context (Figure S1). Then, they were trained on a series of two-context discrimination trials called premise pairs $(\mathrm{A}>\mathrm{B}, \mathrm{B}>$ $\mathrm{C}, \mathrm{C}>\mathrm{D}$, and $\mathrm{D}>\mathrm{E}$; where " $>$ " means that the former context is more preferred than the latter one). Mice should prefer the context in which they were rewarded with a sucrose tablet. Every day, mice were trained on two premise pairs in two sessions, with each session consisting of five trials. During each trial, mice were put into the arena with only two opened contexts, while the other three contexts were closed (Figure 1A). After staying in the assigned context for a consecutive $10 \mathrm{sec}$, mice received a sucrose tablet (Supplementary Video 1). After reaching the criterion for correct performance ( $80 \%$ correct trials) in the four premise pairs (Figure 1B), mice were divided into two groups. The first group was subjected to reinforcement sessions only, while the second group received randomized training sessions in which each pair was presented with a different pair every day (Figure 1A and Methods). Then, mice were subjected to inference (B \& D) and non-inference (A \& E) tests on the last day of training (T1) and in the subsequent 3 days (T2, T3, and T4). Contexts B and D had an equal valence during training as they were the preferred context in one premise pair $(\mathrm{B}>\mathrm{C}$ and $\mathrm{D}>\mathrm{E}$, respectively), and were the avoided context in the other premise pair $(\mathrm{A}>\mathrm{B}$ and $\mathrm{C}>\mathrm{D}$, respectively), such that the performance in the inference test would be purely due to inference from the hierarchy. On the other hand, context A was usually the preferred context, while context E was usually unpreferred; therefore, the performance during tests with the A and E contexts would not be due to the inference. Mice that received reinforcement training only without randomization did not 
exhibit inference in any tests (Figures 1C and 1D); however, they had successfully learnt the original premise pairs (Figure 1B), which indicates that knowledge of the premise pairs did not assure the emergence of inference. On the other hand, mice that received randomized training inferred correctly in all tests except for in T1, as shown by an increased number of correct trials and a decreased latency time to choose the correct context (Figures 1C and 1D). This showed the necessity of randomization during acquisition of the premise pairs knowledge for gaining the inference. In both groups, the percent of correct trials was significantly higher than chance level $(50 \%)$ in the non-inference test (Figure 1E), and their memories of the original premises were intact (Figure 1F).

\section{The emergence of inference requires sleep after training}

The inability to infer correctly in $\mathrm{T} 1$ and the expression of inference in $\mathrm{T} 2$ suggest that inference does not arise online during the repeated training, but instead may require an incubation period or sleep following training. To examine which factor is critical for the inference process, we kept the incubation period intact (the same as before), but mice were sleep-deprived for 4 hours directly after test sessions (Figure 2A). Mice met the criterion for correct training performance, with a non-significant difference in the percent of correct trials across all premise pairs (Figure 2B). Sleep deprivation blocked the inference; the correct performance of mice remained at chance level and their decision making was delayed, even after successive test sessions (Figures 2C and 2D). However, sleep deprivation did not affect performance on the noninference test (Figure 2E) or the original premises' tests (Figure 2F). This suggests that sleep after the last training is crucial for constructing the whole hierarchy of preferences and the subsequent development of inference, but that it is not essential for the A and E pair or for the maintenance of the original premises' representations. The inferential behavior that appeared 
in $\mathrm{T} 2$ in the inference group was not due to learning during $\mathrm{T} 1$ since mice were not provided with sucrose in T1, even when the correct choice was made.

\section{Organizing existing knowledge into a hierarchical order is necessary for inference}

To confirm that mice gained the inference after arranging the premise pairs into a hierarchical order, we trained a group of mice in the same arena, with the same number of trials, but with premise pairs that did not form a complete hierarchy $(\mathrm{A}>\mathrm{B}, \mathrm{B}>\mathrm{C}, \mathrm{E}>\mathrm{D}, \mathrm{D}>\mathrm{C}$; Figure S2A). Mice learnt the premise pairs well and reached the criterion of correct performance (Figure S2C). Lacking the complete hierarchy led to failed inference (Figure S2D and S2E), although mice memorized the original premise pairs well (Figure S2G). Since context A and context $\mathrm{E}$ were usually preferred in the premise pairs training, mice did not prefer either of these during the non-inference test (Figure S2F). These results demonstrate that extracting inference requires the organization of previously acquired knowledge into a hierarchical order.

\section{Prelimbic cortex activity is not required for the emergence of inference}

The mPFC has been proposed to process the mental schema that is utilized to build an inference, and may also compute the inferred outcomes (Brunamonti et al., 2016; Preston and Eichenbaum, 2013; Barron et al., 2020; Spalding et al., 2018; Zeithamova et al., 2012). However, these proposals were derived from lesion and functional brain imaging studies, and lack the causality for temporal and topographic specificity that are necessary for inference development. To directly unravel these ambiguities, we manipulated the activity of mPFC subregion, the prelimbic cortex (PL) during sleep and awake states. The PL of mice was injected with adeno-associated virus $9\left(\mathrm{AAV}_{9}\right)$ encoding a light-sensitive neuronal silencer (ArchT 3.0) with enhanced yellow fluorescent protein under the control of calcium/calmodulin-dependent protein kinase II (CaMKII) to label excitatory neurons with ArchT 3.0 (Figure 3A). Then, mice 
were subjected to the transitive inference task, where optogenetic inhibition was performed during either wakefulness or sleep on the last training day and testing days (Figures 3B and 3C). Mice achieved the standard for correct performance in all premise pairs (Figure 3D). Inhibiting PL activity during sleep or wakefulness after the training did not affect the inference, non-inference test, or premise pairs memories (Figures 3E-3H), which indicates that PL activities during sleep and awake states are not required for the formation of inference.

\section{Anterior cingulate cortex offline computations are crucial for the emergence of inference}

Next, we manipulated another mPFC sub-region, the anterior cingulate cortex (ACC). Mice received injections into the ACC of the same AAV used in Figure 3 (AAV-CaMKII-ArchT 3.0-eYFP) to label excitatory neurons with ArchT 3.0 (Figure 4A). Afterwards, mice completed the transitive inference task, where optogenetic inhibition was performed during either wakefulness, NREM sleep, or REM sleep on the last training day and testing days (Figures 4B and 4C). Mice learnt the premise pairs well, which was reflected by the high number of correct trials that reached the criterion for correct performance (Figure 4D). Optogenetic inhibition of the ACC (Figure S3A) during wakefulness did not impact inference ability, as mice achieved a high correct performance during inference, non-inference, and premise pairs tests (Figures 3E-3H). Conversely, mice that received optogenetic inhibition of the ACC during either NREM or REM sleep failed to infer correctly, and the percent of correct trials was not significantly different from chance level (Figure 3E). Moreover, the latency to choose was significantly longer in the NREM and REM groups than that of the awake group (Figure 3F). These data indicate that ACC computations are necessary for the evolution of inference ability during sleep, but not during wakefulness. However, this perturbation to ACC dynamics had no influence on the non-inference pairs (Figure 3G) or the maintenance of premises knowledge (Figure 3H). 


\section{MEC $\rightarrow$ ACC crosstalk during only REM sleep is sufficient to inspire inference from inadequate training}

Taken together, our results show that inference ability was spontaneously developed during sleep using adequate knowledge that had been acquired during training. However, it remains unclear whether the idling brain can create inference artificially from insufficient knowledge. To answer this question and examine the circuit underlying inference, mice were injected into the medial entorhinal cortex (MEC), which is thought to be involved in transitive inference (Dusek and Eichenbaum, 1997; Buckmaster et al., 2004), with $\mathrm{AAV}_{9}$ encoding light-sensitive neuronal activator (oChIEF) under the control of human synapsin (hSyn) 1 promoter (Figure 5A). Mice were exposed to an incomplete/modified protocol of the transitive inference task, in which the randomized training, which is necessary to create inference (Figures $1 \mathrm{C}$ and 1D), was replaced with optogenetic activation of neuronal terminals of the MEC in the ACC at $4 \mathrm{~Hz}$ during either NREM or REM sleep (Figures 5B, 5C, and S3B). All groups achieved the criterion for correct performance during training of the premises (Figure 5D). Without both randomized training and $\mathrm{MEC} \rightarrow \mathrm{ACC}$ circuit activation, mice could not infer correctly, as demonstrated by a number of correct trials that was not significantly different from chance level in the B and D context tests (Figure 5E). However, artificial activation of the MEC $\rightarrow$ ACC network during REM, but not NREM, sleep resulted in inference in T2, T3, and T4, in which mice exhibited significantly more correct trials than those seen in T1, and significantly higher than chance level; faster selection of the rewarded context was also found (Figures 5E, 5F, and S4). These results highlight the dissociable contribution of sleep stages (NREM and REM sleep) in inference processing, and indicates that activating the cortical network during REM sleep is sufficient for the creation of novel conclusions. All groups were proficient during testing of the non-inference and the premise pairs (Figures $5 \mathrm{G}$ and $5 \mathrm{H}$ ). 


\section{DISCUSSION}

Our study clarifies the superiority of the subconscious brain over the conscious brain in restructuring existing stores of information before abstracting logical inference. During sleep, multiple related memories are connected to construct a knowledge structure, which facilitates innovative inference, a capacity that was not present shortly after learning. The discrepancy in the performance after awake and sleep manipulations indicates the necessity of offline, but not online, cortical activity to trigger inference. Sleep deprivation and optogenetic inhibition experiments revealed the ability to interfere with the emergence of inference while preserving memories of the original premises, thereby suggesting that stored knowledge and inferential information have unique representations and/or distinct locations in the brain. The artificial induction of inference by initiating communication between the MEC and ACC implies that the dynamic interplay between cortical neural codes for related experiences is critically important for the emergence of inferential behavior.

Our study demonstrates that offline brain activity allows the abstraction of new information from previous experiences, which differs from previous findings showing the online emergence of inferential knowledge during subsequent experiences (Barron et al., 2020; Liu et al., 2019). Previous study on human subjects utilized online priming of past knowledge with instructions during a novel experience, which led to successful performance in an applied learning task (Liu et al., 2019). Another recent study applied a sensory pre-conditioning task and found that the association between two learning experiences occurred online during the second experience (Barron et al., 2020). This previous study shows that successful inferential behavior occurs before the appearance of synchronized reactivation of the representation of both experiences, which may reflect the reactivation of the inferential behavior rather than its trigger. Furthermore, causal evidence for the link between inference and offline brain activity has been lacking. Our study demonstrates the offline and spontaneous emergence of inference 
without prior priming, and provides causal evidence for the necessity and sufficiency of cortical activity during sleep to inspire inferential knowledge.

REM sleep is characterized by vivid dreams (Lewis et al., 2018). Prior investigations into the role of REM sleep in cognition has found that it is necessary for memory consolidation (Boyce et al., 2016) and could be involved in creative problem solving by enhancing the formation of associative networks (Cai et al., 2009; Lewis et al., 2018). Here, we present evidence of a causal link between REM sleep and creativity using loss and gain of function experiments. Activating the MEC $\rightarrow$ ACC network at $4 \mathrm{~Hz}$ during REM sleep may provide an ideal setting for dreaming the inference, thus leading to innovative decisions. The dissociable roles of REM and NREM sleep in processing the inference suggest that there are distinct offline mechanisms underlying the formation of knowledge networks. Since NREM sleep precedes REM sleep, we can propose that NREM sleep prepares the knowledge network for REMinduced restructuring and the creation of novel associations (Lewis et al., 2018). This may explain why NREM sleep is crucial, but not sufficient, for the emergence of inference. The greater contribution of REM sleep over NREM sleep in inference development supports earlier findings that performance in anagram word puzzles is better after awakening from REM sleep than after awakening from NREM sleep (Walker et al., 2002).

The capacity of REM sleep to facilitate inference from inadequate knowledge could inspire the development of novel approaches to boost cognitive performance. Moreover, upregulation of plasticity-related genes during REM sleep (Ribeiro et al., 1999; Ribeiro et al., 2002) allows for bidirectional plasticity that may alter the structure of synaptic networks. Artificial activation of cortical networks during REM sleep (Figure 5) may modify the synaptic network structure, thus reorganizing the knowledge network and facilitating inference. The ability of REM sleep to flexibly restructure our knowledge could offer new behavioral 
repertoires to facilitate higher-order brain functions, such as implicit learning, decision making, and creative thinking.

Synchronized offline reactivations are necessary for assimilating two subtly related memories, and eventually revealing the implicit commonality between them (Aly et al., 2021). Similarly, offline optogenetic activation of the MEC $\rightarrow$ ACC circuit may lead to simultaneous co-reactivation of the cortically-coded knowledge before extracting the inference, which indicates that offline co-reactivations could underlie sleep-triggered creativity.

\section{ACKNOWLEDGMENTS}

We thank Khaled Ghandour and Ali Choucry (University of Toyama) for their valuable discussions and suggestions, and Masanori Nomoto (University of Toyama) for his help in setting the automatic detection of sleep stages. We thank all members of the Inokuchi Laboratory for their discussions and support. We thank Mika Ito and Naomi Takino (Jichi Medical University) for their help with the production of the AAV vectors. Also, we thank Noriaki Ohkawa (Dokyyo University) for his help in providing the materials used to build the behavioral arena. We would like to thank Karl Deisseroth (Stanford University) for providing us with pAAV-CaMKII-ArchT 3.0-EYFP. We also thank Ayumu Konno and Hirokazu Hirai (Gunma University) for providing us with the virus preparation protocol.

This work was supported by the JSPS KAKENHI (grant number JP18H05213), the Core Research for Evolutional Science and Technology (CREST) program (JPMJCR13W1) of the Japan Science and Technology Agency (JST), a Grant-in-Aid for Scientific Research on Innovative Areas "Memory dynamism" (JP25115002) from MEXT, and the Takeda Science Foundation to K.I.; JSPS KAKENHI (grant number JP19K16892) to K.A.; and the Uehara Memorial Foundation scholarship to M.A.

\section{AUTHOR CONTRIBUTIONS}


K.A. and K.I. designed the experiments and wrote the manuscript. K.A., K.C., and M.A. performed the experiments. K.A. analyzed the data. S.M. and R.O-S. prepared adenoassociated viruses. K.I. supervised the entire project.

\section{DECLARATION OF INTERESTS}

S.M. owns equity in a company, Gene Therapy Research Institution, that commercializes the use of AAV vectors for gene therapy applications. To the extent that the work in this manuscript increases the value of these commercial holdings, S.M. has a conflict of interest. The other authors declare no competing interests.

\section{FIGURE TITLES AND LEGENDS}

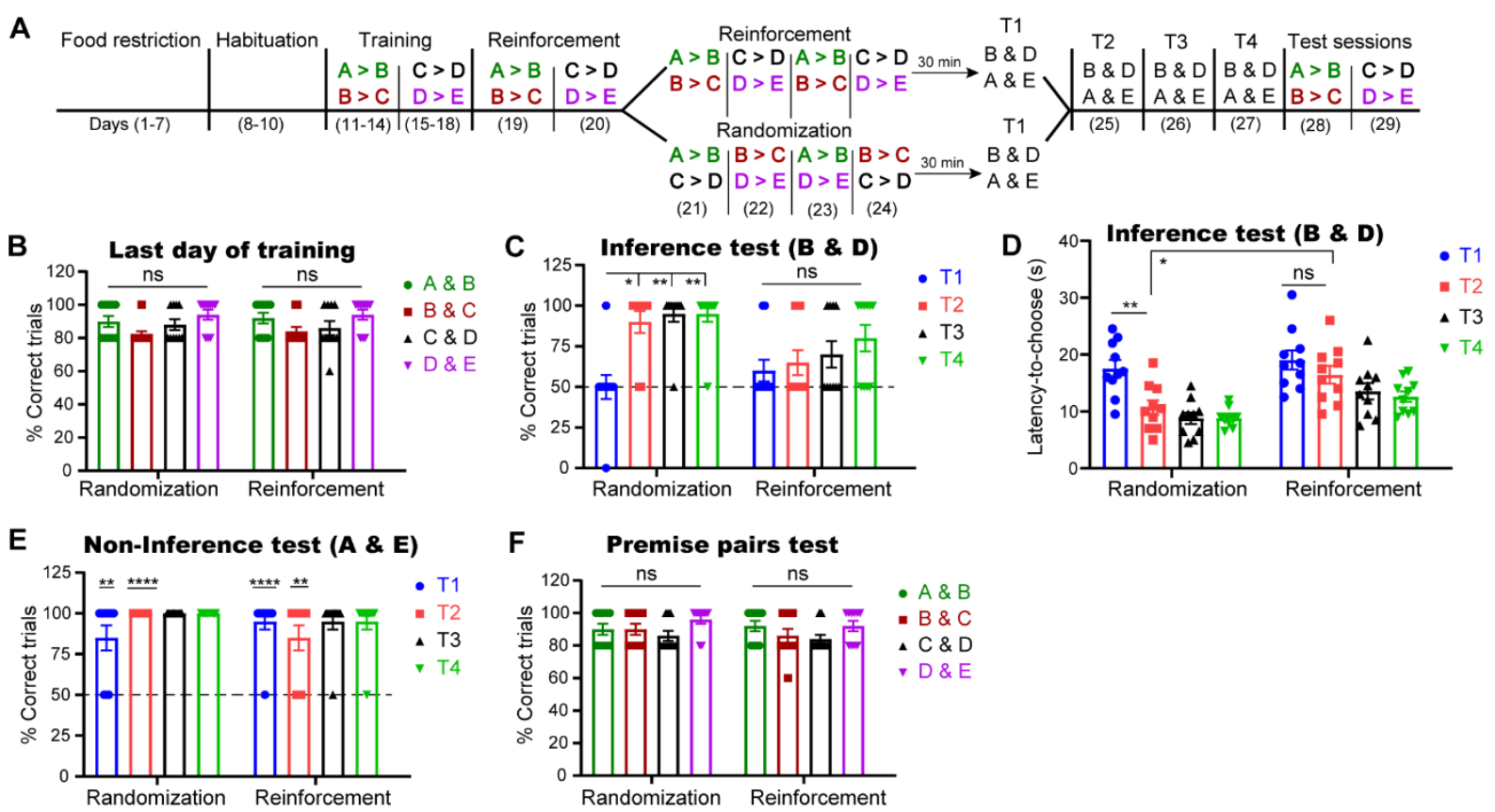

Figure 1. Randomizing existing knowledge is necessary for the emergence of inferential

\section{behavior}

(A) The behavioral schedule used to establish the transitive inference paradigm in mice. The contexts' hierarchy was as follows: A $>$ B $>$ C $>$ D $>$ E. 
(B) Performance during the last day of training (day 14 for A $>$ B and B $>$ C; day 18 for C $>$ D and $\mathrm{D}>\mathrm{E}$ ) for each premise pair was calculated as the percent of correct trials out of the total number of trials.

(C to F) Performance during test sessions; the percent of correct trials in the inference test (C), the latency time to choose in the inference test (D), in the non-inference test (E), and in the original premise pairs test $(\mathrm{F}) . \mathrm{T} 1$, test 1 ; $\mathrm{T} 2$, test 2 ; T3, test 3 ; T4, test $4 . n=10$ mice/group.

Statistical comparisons were made using a two-way repeated-measures analysis of variance (ANOVA) with Tukey's multiple comparison test within groups (B to F) and Holm-Sidak's test between groups (D). In the non-inference test (E), the statistical significance denotes the comparison between performance of the two groups relative to chance level $(50 \%) .{ }^{*} P<0.05$; ${ }^{* *} P<0.01 ; * * * * P<0.0001 ;$ ns, not significant $(P>0.05)$. Data are presented as the mean \pm standard error of the mean (SEM).
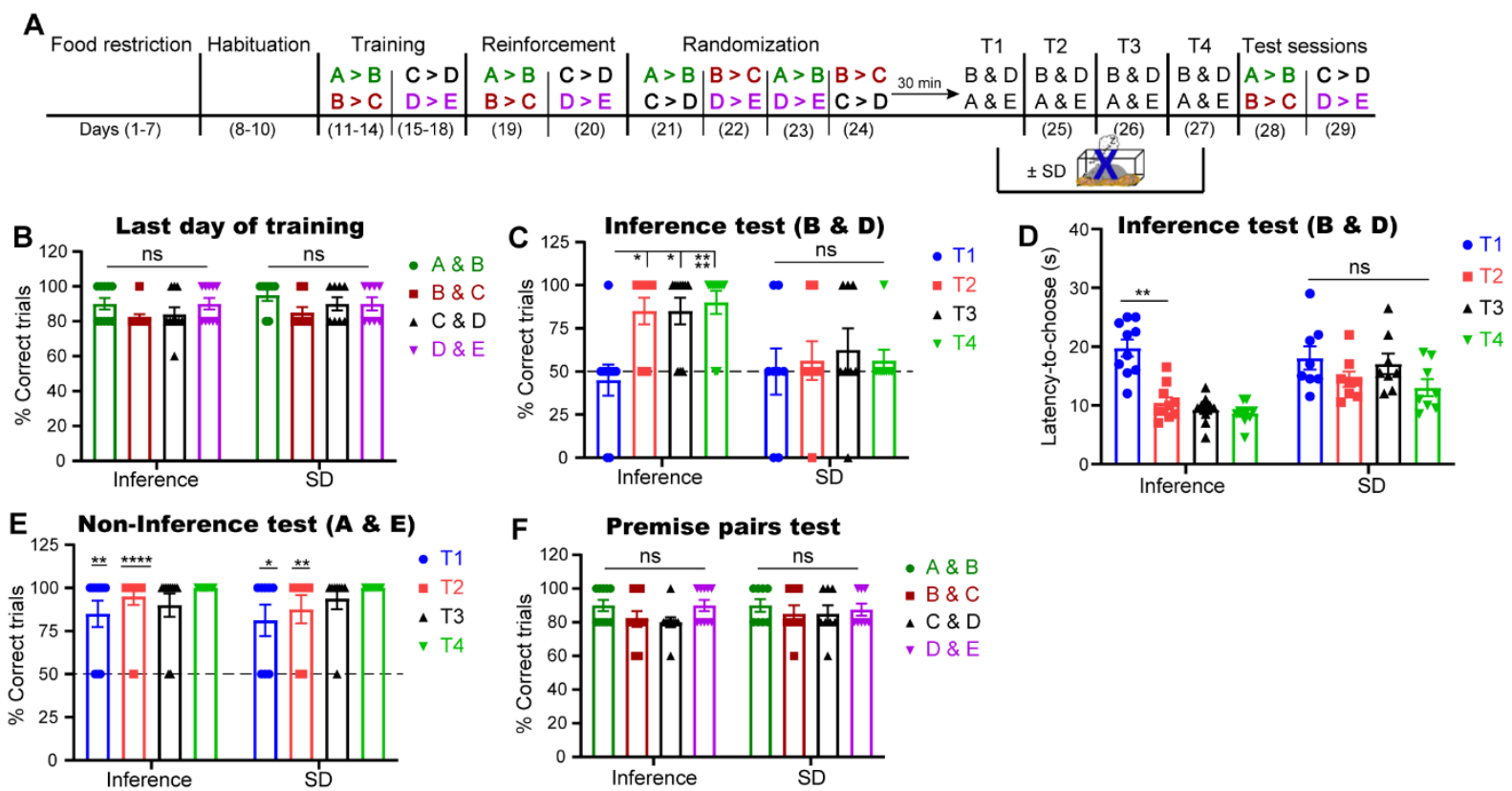

Figure 2. The emergence of inference requires sleep after training

(A) Behavioral protocol for the transitive inference paradigm; SD, sleep deprivation. 
(B) Percent of correct trials during the last day of training (day 14 for A $>$ B and B $>$ C; day 18 for $\mathrm{C}>\mathrm{D}$ and $\mathrm{D}>\mathrm{E}$ ) for each premise pair.

(C to F) Performance during test sessions; percent of correct trials during the inference test (C), latency time to choose during the inference test (D), during the non-inference test (E), and during testing of the original premise pairs $(\mathrm{F}) . \mathrm{T} 1$, test 1 ; T2, test 2 ; T3, test 3 ; T4, test $4 . n=$ 10 mice for the inference group; $n=8$ mice for the sleep deprivation (SD) group.

Statistical comparisons were made using a two-way repeated-measures ANOVA with Tukey's multiple comparison test (B to F). In the non-inference test (E), the statistical significance denotes the comparison between performance of the two groups relative to chance level (50\%). $* P<0.05 ; * * P<0.01 ; * * * * P<0.0001$; ns, not significant $(P>0.05)$. Data are presented as the mean \pm standard error of the mean (SEM).

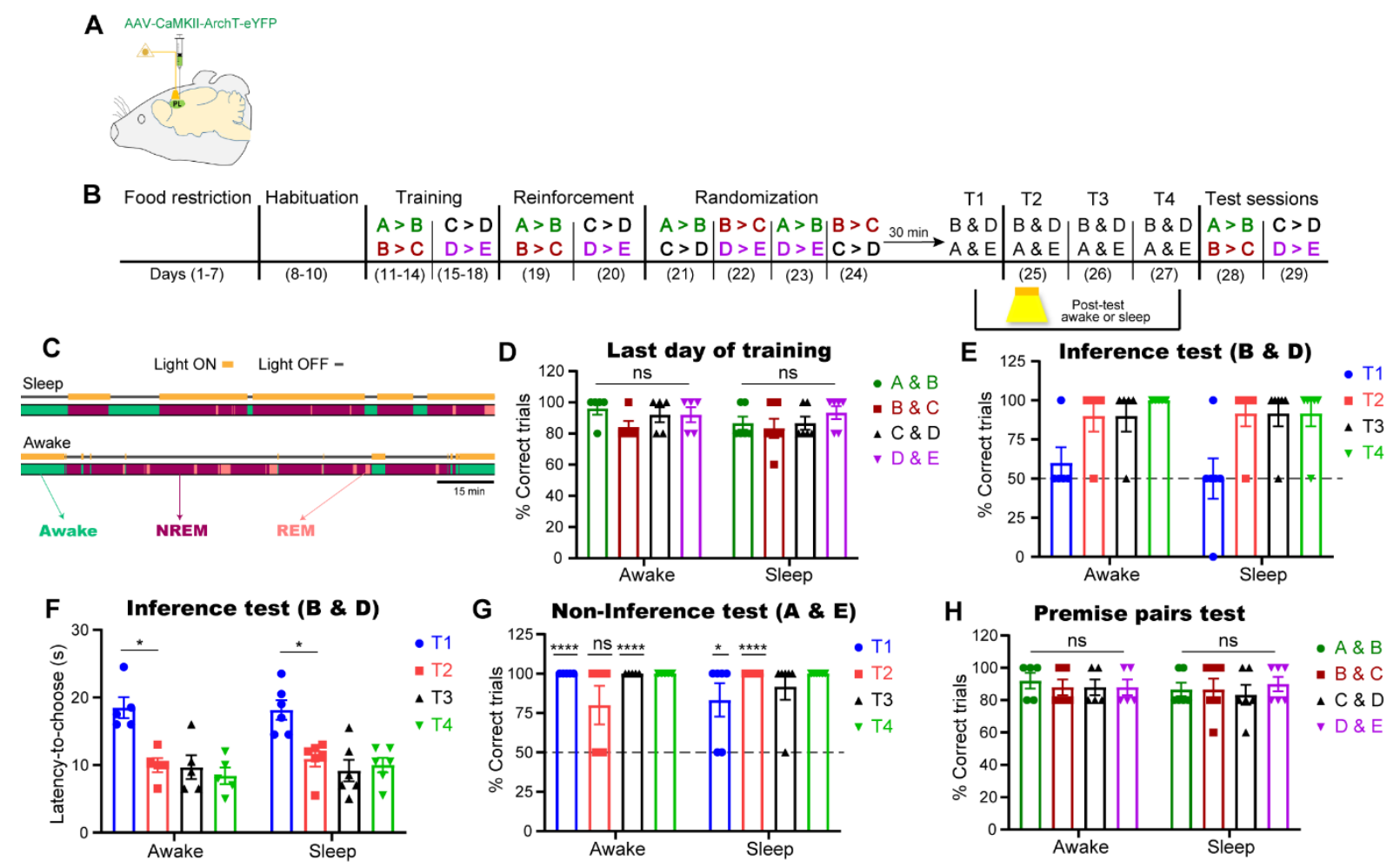

Figure 3. Prelimbic cortex activity is not required for the emergence of inference

(A) Labeling of excitatory neurons of the prelimbic cortex (PL) with ArchT. 
(B) The behavioral schedule used to manipulate PL activity during sleep or awake periods after test sessions.

(C) Diagram showing the state-specific manipulation. Scale bar, 15 minutes.

(D) Performance during the last day of training (day 14 for A $>$ B and B $>$ C; day 18 for $\mathrm{C}>\mathrm{D}$ and $\mathrm{D}>\mathrm{E}$ ) for each premise pair.

(E to H) Performance during the test sessions; the percent of correct trials during the inference test $(\mathrm{E})$, latency time to choose during the inference test $(\mathrm{F})$, during the non-inference test $(\mathrm{G})$, and during the original premise pairs test $(\mathrm{H}) . \mathrm{T} 1$, test 1 ; T2, test 2 ; T3, test 3 ; T4, test $4 . n=5$ mice for the awake group; $n=6$ mice for the sleep group.

Statistical comparisons were made using a two-way repeated-measures analysis of variance (ANOVA) with Tukey's multiple comparison test (D to H). In the non-inference test (G), the statistical significance denotes the comparison between performance of the two groups relative to the chance level $(50 \%)$. ${ }^{*} P<0.05$; $* * * P<0.0001$; ns, not significant $(P>0.05)$. Data are presented as the mean \pm standard error of the mean (SEM). 


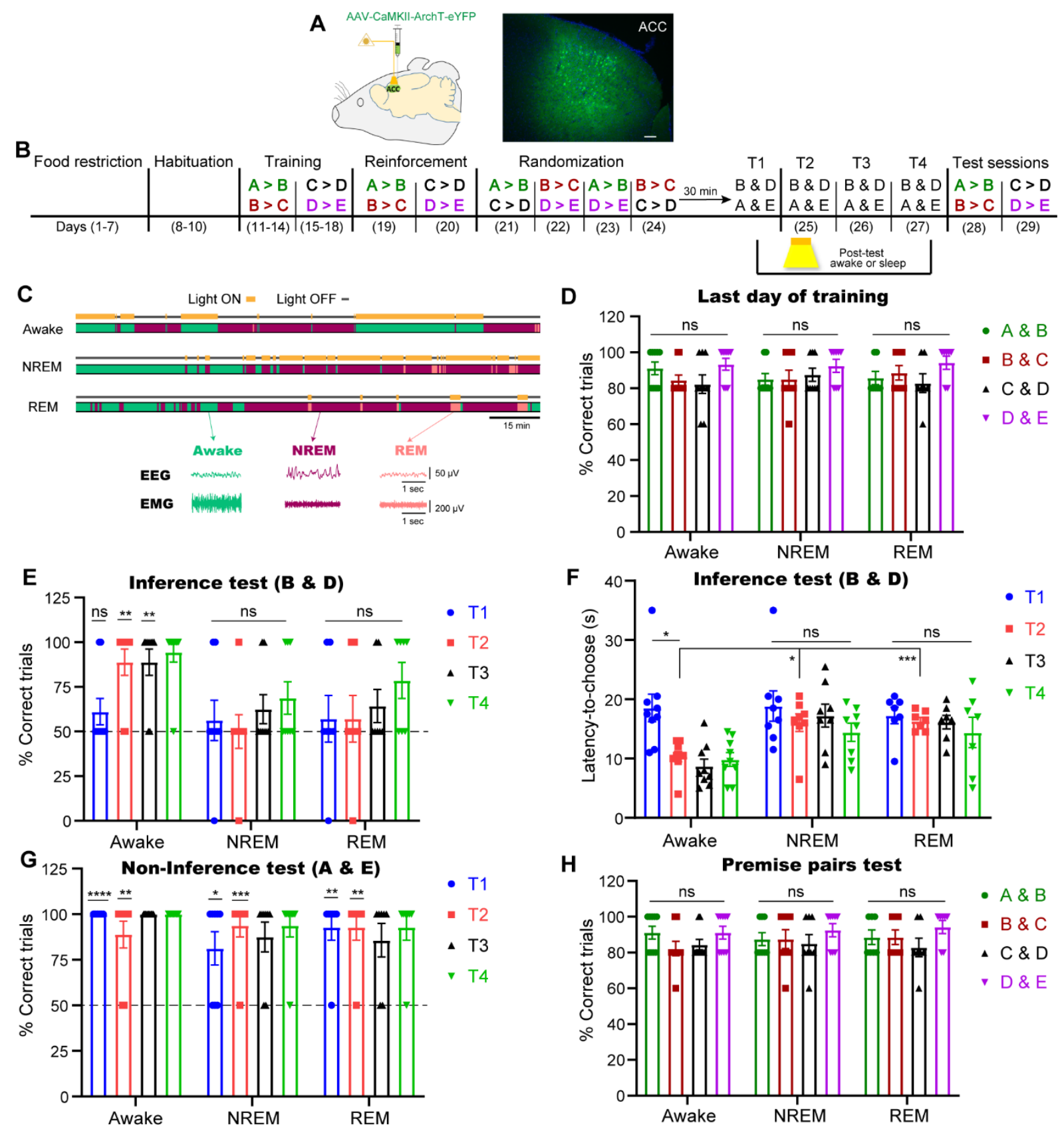

Figure 4. Anterior cingulate cortex offline computations are crucial for the emergence of inference

(A) Labelling excitatory neurons of the ACC with ArchT (left), and the expression of ArchTeYFP (green) in the ACC (right). Blue, 4',6-diamidino-2-phenylindole (DAPI) staining. Scale bar, $100 \mu \mathrm{m}$.

(B) Behavioral schedule used to manipulate ACC activity during sleep and awake periods after test sessions. 
(C) Diagram showing the state-specific manipulation (top) and representative electroencephalogram (EEG) and electromyography (EMG) (bottom) traces. Scale bar, 15 minutes.

(D) Performance during the last day of training (day 14 for $\mathrm{A}>\mathrm{B}$ and $\mathrm{B}>\mathrm{C}$; day 18 for $\mathrm{C}>\mathrm{D}$ and $\mathrm{D}>\mathrm{E}$ ) for each premise pair.

(E to H) Performance during test sessions; percent of correct trials during the inference test (E), latency time to choose during the inference test $(F)$, during the non-inference test $(\mathrm{G})$, and during the original premise pairs test $(\mathrm{H})$. T1, test 1 ; T2, test 2 ; T3, test 3 ; T4, test $4 . n=9$ mice for the awake group; $n=8$ mice for the non-rapid eye movement (NREM) sleep group; $n=7$ mice for the rapid eye movement (REM) sleep group.

Statistical comparisons were made using two-way repeated-measures analysis of variance (ANOVA) with Tukey's multiple comparison test (D to H). In (E and G), the statistical significance denotes the comparison between performance relative to the chance level (50\%). ${ }^{*} P<0.05 ;{ }^{* *} P<0.01 ; * * * P<0.001 ; * * * * P<0.0001$; ns, not significant $(P>0.05)$. Data are presented as the mean \pm standard error of the mean (SEM). 

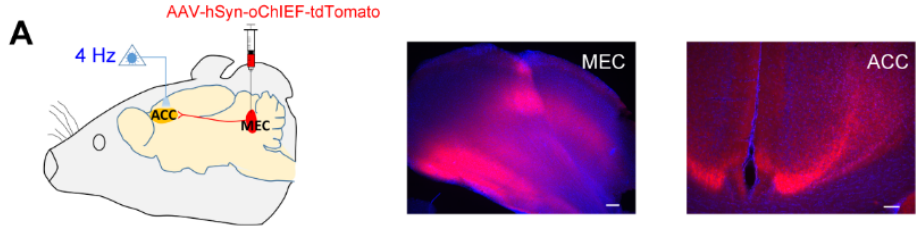

B

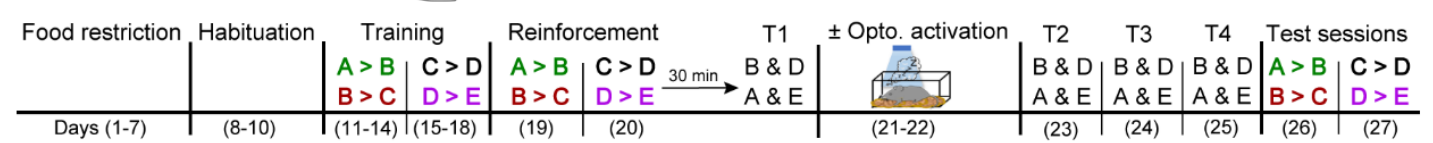

C

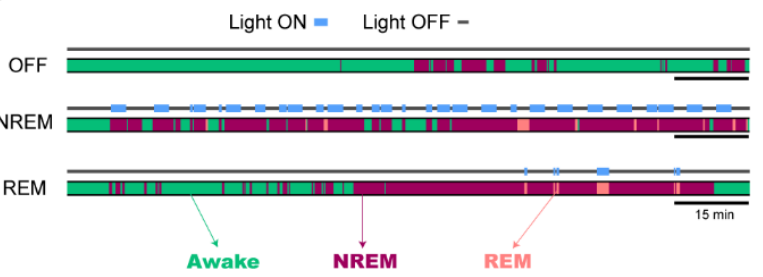

E

Inference test (B \& D)

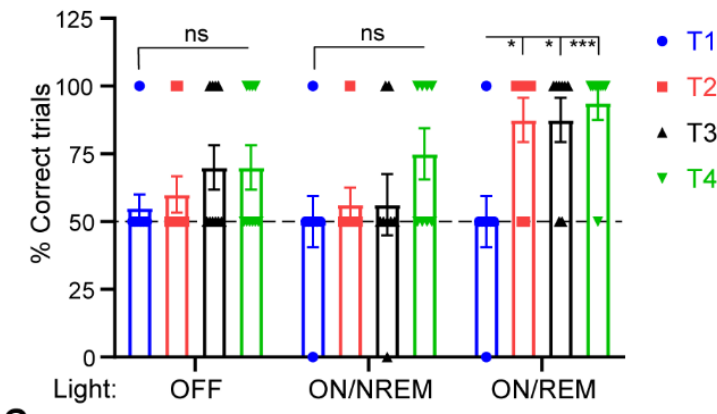

G
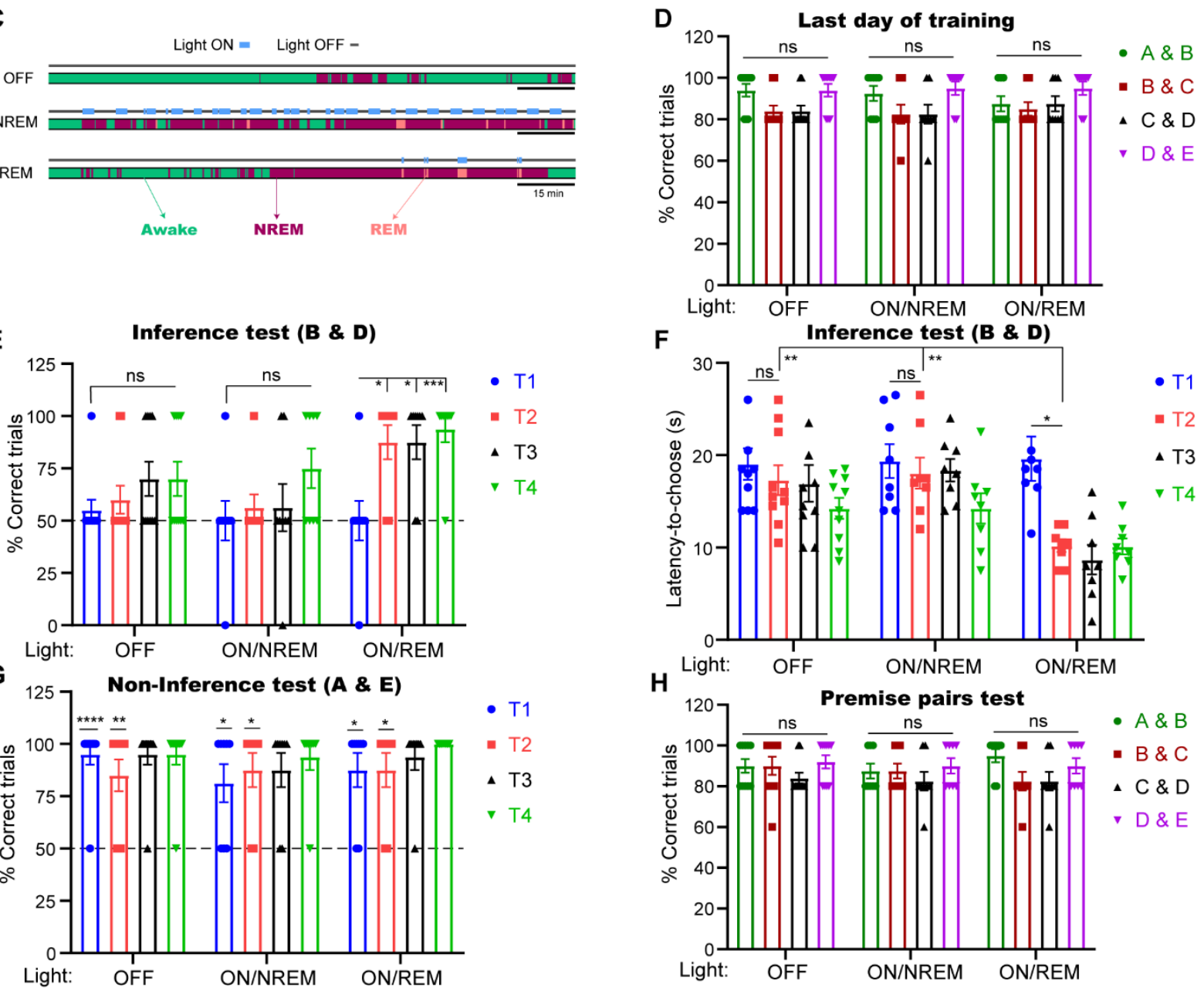

Figure 5. MEC $\rightarrow \mathrm{ACC}$ crosstalk during only REM sleep is sufficient to inspire inference

\section{from inadequate training}

(A) The strategy for labelling MEC neurons and targeting their terminals in the ACC (left), and expression of oChIEF-tdTomato (red) in MEC neurons (middle) and their terminals in the ACC (right). Blue, 4',6-diamidino-2-phenylindole (DAPI) staining. Scale bars, $100 \mu \mathrm{m}$.

(B) The behavioral schedule used to manipulate the MEC $\rightarrow$ ACC circuit during different sleep stages.

(C) Diagram showing the sleep stage-specific manipulation. Scale bar, 15 minutes. 
(D) Performance during the last day of training (day 14 for $\mathrm{A}>\mathrm{B}$ and $\mathrm{B}>\mathrm{C}$; day 18 for $\mathrm{C}>\mathrm{D}$ and $\mathrm{D}>\mathrm{E}$ ) for each premise pair.

(E to H) Performance during test sessions; the percent of correct trials during the inference test (E), the latency time to choose during the inference test $(F)$, during the non-inference test $(G)$, and during the original premise pairs test $(\mathrm{H})$. T1, test 1 ; T2, test 2 ; T3, test 3 ; T4, test $4 . n=$ 10 mice for the light off group; $n=8$ mice for the non-rapid eye movement (NREM) sleep group; $n=8$ mice for the rapid eye movement (REM) sleep group.

Statistical comparisons were made using a two-way repeated-measures analysis of variance (ANOVA) (D to H) with Newman-Keuls multiple comparison test (E) and Tukey's multiple comparison test (D, F, G and $H)$. In the non-inference test $(G)$, the statistical significance denotes the comparison between performance relative to the chance level $(50 \%)$. $* P<0.05$; ${ }^{* *} P<0.01 ; * * * P<0.001 ; * * * * P<0.0001 ;$ ns, not significant $(P>0.05)$. Data are presented as the mean \pm standard error of the mean (SEM). 


\title{
STAR METHODS
}

\section{RESOURCE AVAILABILITY}

\section{Lead Contact}

Further information and requests for resources and reagents should be directed to and will be

fulfilled by the Lead Contact, Kaoru Inokuchi (inokuchi@med.u-toyama.ac.jp).

\section{Materials availability}

This study did not generate new unique reagents.

\section{Data and Code Availability}

All data, codes, and resources that supported the findings of this study are available from the lead contact upon reasonable request.

\section{METHOD DETAILS}

\begin{abstract}
Animals
Naïve wild-type male C57BL/6J mice were purchased from Sankyo Labo Service Co. Inc. (Tokyo, Japan) and maintained on a $12 \mathrm{~h}$ light/dark cycle at a controlled temperature $\left(24^{\circ} \mathrm{C} \pm\right.$ $\left.3^{\circ} \mathrm{C}\right)$ and humidity $(55 \% \pm 5 \%)$ with free access to food and water. Mice used in behavioral experiments were 14-20 weeks old. All experimental procedures with animals were congruent with the guidelines of the National Institutes of Health. The Animal Care and Use Committee of the University of Toyama approved all animal experiments.
\end{abstract}

\section{Viral constructs}

For the optogenetic inhibition experiment (Figure 3 and Figure S3), the AAV viral vector AAV-CaMKII-ArchT-eYFP $(3.15 \times 1013 \mathrm{vg} / \mathrm{mL})$ was used. pAAV-CaMKII-ArchT-eYFP was kindly donated by Dr. K. Deisseroth. The recombinant AAV9 production was performed using a minimal purification method, and viral genomic titre was subsequently calculated as described previously (Konno and Hirai, 2020). Briefly, pAAV recombinant vector was produced using HEK293 T cells (AAV293; 240073, Agilent Tech, CA, USA) cultured in 15 cm dishes (Corning, NY, USA). Cultured cells were maintained in Dulbecco's Modified Eagle Medium (D-MEM) (11995-065, GIBCO life technologies, USA) supplemented with $10 \%$ fetal bovine serum (FBS) (10270106, GIBCO life technologies, USA), 1\% $2 \mathrm{mM}$ L-Glutamine (25030-149, GIBCO Life Technologies, USA), 1\% $10 \mathrm{mM}$ non-essential amino acid (MEM NEAA 100x, 11140-050, GIBCO Life Technologies, USA), and 1\% (100x) penicillinstreptomycin solution (15140-148, GIBCO Life Technologies, USA). Confluent (70\%) HEK293 T cells were transfected using medium containing the constructed expression vector, pRep/Cap, and pHelper (240071, Agilent Technologies, Santa Clara, CA, USA) mixed with the transfection reagent polyethyleneimine hydrochloride (PEI Max, 24765-1, Polysciences, 
Inc., Warrington, PA, USA) at a 1:2 ratio (W/V). After $24 \mathrm{~h}$, the transfection medium was discarded, and cells were incubated for another 5 days in an FBS-free maintenance medium. On day 6, the AAV-containing medium was collected and purified from cell debris using a $0.45 \mu \mathrm{m}$ Millex-HV syringe filter (SLHV033RS, Merck Millipore, Germany). The filtered medium was concentrated and diluted with D-PBS (14190-144, GIBCO Life Technologies, USA) twice using the Vivaspin 20 column (VS2041, Sartorius, Germany) after blocking the column membrane with $1 \%$ bovine serum albumin (01862-87, Nacalai Tesque, Inc., Japan) in PBS. To further calculate the titre, degradation of any residual cDNA in the viral solution from production was first assured by benzonase nuclease treatment (70746, Merck Millipore, Germany). Subsequently, viral genomic DNA was obtained after digestion with proteinase K (162-22751, FUJIFILM Wako Pure Chemical, Osaka, Japan), extraction with phenol/chloroform/isoamyl alcohol 25:24:1 v/v, then precipitation with isopropanol and final dissolution in TE buffer (10 mM Tris [pH 8.0], $1 \mathrm{mM}$ EDTA). Titer quantification for each viral solution, referenced to that of the corresponding expression plasmid, was done by realtime quantitative PCR (qPCR) using THUDERBIRD SYBR qPCR Master Mix (QRS-201, Toyobo Co., Ltd, Japan) with the primers 5'-GGAACCCCTAGTGATGGAGTT-3' and 5'CGGCCTCAGTGAGCGA-3' targeting the inverted terminal repeat (ITR) sequence. The cycling parameters were adjusted as follows: initial denaturation at $95^{\circ} \mathrm{C}$ for $60 \mathrm{sec}$, followed by 40 cycles of $95^{\circ} \mathrm{C}$ for $15 \mathrm{sec}$ and $60^{\circ} \mathrm{C}$ for $30 \mathrm{sec}$.

For the optogenetic activation experiment (Figure 4), the AAV viral vector AAV-hSyn1oChIEF-tdTomato $(2.1 \times 1013 \mathrm{vg} / \mathrm{mL})$ was used. pAAV-hSyn1-oChIEF-tdTomato was purchased from Addgene (Cambridge, MA, Plasmid \#50977). Recombinant AAV vectors were produced by transient transfection of HEK293 cells with the vector plasmid, an AAV3 rep and AAV9 vp expression plasmid, and an adenoviral helper plasmid, pHelper (Agilent Technologies, Santa Clara, CA), as previously described (Iida et al., 2013; Li et al., 2006).

\section{Surgery}

Mice (10-14 weeks old) were given an intraperitoneal anesthesia injection containing 0.75 $\mathrm{mg} / \mathrm{kg}$ medetomidine (Domitor; Nippon Zenyaku Kogyo Co., Ltd., Japan), $4.0 \mathrm{mg} / \mathrm{kg}$ midazolam (Fuji Pharma Co., Ltd., Japan), and $5.0 \mathrm{mg} / \mathrm{kg}$ butorphanol (Vetorphale, Meiji Seika Pharma Co., Ltd., Japan) before being placed, when sedated, on a stereotactic apparatus (Narishige, Tokyo, Japan). After surgery, an intramuscular injection of $1.5 \mathrm{mg} / \mathrm{kg}$ atipamezole (Antisedan; Nippon Zenyaku Kogyo Co., Japan), an antagonist of medetomidine, was administered to boost recovery from sedation. Mice were home caged for 3 weeks to recover from surgery before initiating behavioral experiments. All virus injections were done using a $10 \mu \mathrm{L}$ Hamilton syringe (80030, Hamilton, USA) that was fitted with a mineral oil-filled glass needle and wired to an automated motorized microinjector IMS-20 (Narishige, Japan).

For the optogenetic inhibition experiments (Figure 3, and Figure S3), $500 \mathrm{~nL}$ of AAV viral vector were injected at $100 \mathrm{~nL}$ min-1 bilaterally into either the ACC (from bregma: +0.3 $\mathrm{mm}$ anteroposterior [AP], $\pm 0.35 \mathrm{~mm}$ mediolateral [ML]; from the skull surface: $+1.5 \mathrm{~mm}$ dorsoventral [DV]) or prelimbic cortex (PL) (from bregma: $+2.0 \mathrm{~mm} \mathrm{AP,} \pm 0.35 \mathrm{~mm} \mathrm{ML}$; from the skull surface: $+1.8 \mathrm{~mm} \mathrm{DV}$ ). The glass injection tip was maintained after injection at the target coordinates for an additional $5 \mathrm{~min}$ before being removed. Then, a double-guide cannula (C2002GS-5-0.7/SPC, diameter $0.29 \mathrm{~mm}$, Plastics One Inc., USA) composed of two $0.7 \mathrm{~mm}$ spaced stainless-steel pipes protruding for $2 \mathrm{~mm}$ from the plastic cannula body was bilaterally inserted either $1.0 \mathrm{~mm}$ ventral to the skull surface at the ACC coordinates or $1.3 \mathrm{~mm}$ ventral to the skull surface at the PL coordinates. Guide cannulas were fixed using dental cement (Provinice, Shofu Inc., Japan) that was used to fix micro-screws that were anchored into the skull near bregma and lambda. After complete fixation, a dummy cannula (C2002DCS-5- 
0.7/SPC, protrusion $0 \mathrm{~mm}$, Plastics One Inc., USA) was attached to the guide cannula to protect from particulate matter.

In parallel, a custom-built electroencephalogram/electromyography (EEG/EMG) 5-pin system was installed into the skull as previously described (Miyamoto et al., 2016). Briefly, electrodes were screwed into the skull over the parietal cortex for EEG recording, over the right cerebellar cortex as a ground, and over the left cerebellar cortex as a reference. Additionally, two wires were implanted into the neck muscle for EMG recording. Finally, dental cement was used to fix all system screws in place.

For the optogenetic activation experiment (Figure 4), $500 \mathrm{~nL}$ of the AAV viral vector was injected at $100 \mathrm{~nL} \mathrm{~min}-1$ bilaterally into the MEC (from bregma: $+4.8 \mathrm{~mm} \mathrm{AP,} \pm 3.3 \mathrm{~mm} \mathrm{ML}$, $+3.3 \mathrm{~mm} \mathrm{DV}$ ). The remaining procedure was as described earlier in the optogenetic inhibition section.

\section{Transitive inference task}

The behavioral experiments were done in soundproof room. The arena consists of 5 different contexts (A, B, C, D, and E; Figure S1A). Context A was a gray triangle $(200 \mathrm{~mm}$ length $\times 300$ $\mathrm{mm}$ height) with a smooth, gray acrylic floor and walls without any patterns. Context $\mathrm{B}$ was a gray square $(200 \mathrm{~mm}$ length $\times 200 \mathrm{~mm}$ width $\times 300 \mathrm{~mm}$ height $)$ with a green plastic floor with a pointy texture and walls without any patterns. Context $\mathrm{C}$ was a blue square $(200 \mathrm{~mm}$ length $\times 200 \mathrm{~mm}$ width $\times 300 \mathrm{~mm}$ height) with a smooth, blue acrylic floor and walls without patterns. Context D was a transparent square $(200 \mathrm{~mm}$ length $\times 200 \mathrm{~mm}$ width $\times 300 \mathrm{~mm}$ height $)$ with a spongy, orange floor and walls that were covered with a characteristic pattern (black circles on a white background). Context $\mathrm{E}$ was a transparent triangle ( $200 \mathrm{~mm}$ length $\times 300 \mathrm{~mm}$ height) with a smooth, transparent acrylic floor and walls that were covered with a characteristic pattern (black vertical lines on a white background).

Food restriction: Mice were kept under a food restriction protocol during the task. Mice were provided with one $3 \mathrm{~g}$ food pellet and one $0.05 \mathrm{~g}$ sucrose tablet per day until mice reach $80-85 \%$ of their original weight. The sucrose tablets were put in a small Petri dish inside the home cage during the first two stages (food restriction and arena habituation); the dish was removed after starting the training stage and was never put it back, which served to teach mice that they would no longer receive any sucrose tablets in the home cage and the only way to receive the reward in the contexts was to perform the task correctly.

Arena habituation: On the first day, mice were put in each context separately for $5 \mathrm{~min}$. The contexts were closed to force mice to explore each context for the entire $5 \mathrm{~min}$. The exposure to the contexts was random across mice (for example, one mouse was placed in $\mathrm{A}$ then $\mathrm{C}$ then $\mathrm{D}$ then $\mathrm{B}$ then $\mathrm{E}$, and another mouse was placed in $\mathrm{C}$ then $\mathrm{B}$ then $\mathrm{E}$ then $\mathrm{A}$ then D). On the second and third days, all contexts were open and mice were put in the start point for free exploration of the whole arena for $15 \mathrm{~min}$.

Training: The 14-day training phase was divided into 4 consecutive days for the first two pairs, 4 days for the other two pairs, 2 days reinforcement, and 4 days randomization. Every day, mice were exposed to two sessions, and each session consisted of five trials for a premise pair without inter-trial intervals. The four premise pairs were $A>B, B>C, C>D$, and D $>$ E. Therefore, the hierarchy was $\mathrm{A}>\mathrm{B}>\mathrm{C}>\mathrm{D}>\mathrm{E}$. For the incomplete hierarchy experiment (Figure S2), the four premise pairs were A > B, B > C, E > D, and D > C. Therefore, the hierarchies were $\mathrm{A}>\mathrm{B}>\mathrm{C}$ and $\mathrm{E}>\mathrm{D}>\mathrm{C}$. Premise pair training was considered successful when mice reached $80 \%$ correctness.

In the first trial of every session, mice were put at the starting point and allowed to explore the arena and enter the two contexts to identify the learned pair. After entering both contexts once, if they entered the correct context again and remained there for more than $10 \mathrm{sec}$, they received the sucrose tablet, and the trial ended after the tablet had been consumed. If they 
stayed in the non-rewarded context (wrong choice) for more than $10 \mathrm{sec}$, the trial ended, and in the next correct trial they received the sucrose tablet after $20 \mathrm{sec}$ (rather than $10 \mathrm{sec}$ ). After each trial, mice were directly returned to the starting point to start the next trial without any inter-trial interval. After completing all trials, mice were returned to their home cage for 30 min before starting the next session. After finishing two sessions, mice returned to their home cages and received a $2-\mathrm{g}$ food pellet.

For randomization during training, every premise pair was presented with one of the other three pairs in one day. This is different from training with reinforcement, in which the A \& B pair is usually presented with the B \& C pair, and the C \& D pair is usually presented with the D \& E pair. For the optogenetic activation experiment (Figure 4), training was done for 10 days only without the 4 days of randomization.

Testing: After the training phase, mice were exposed to two types of testing for 4 consecutive days. The inference test utilized a novel pair (B \& D), while the non-inference test utilized another novel pair (A \& E). Test 1 was done on the last day of training, while tests 2 , 3 , and 4 were done on the following 3 days.

Every day, mice were exposed to two sessions, each of which consisted of two trials for each test without any inter-trial intervals. After completing all trials, mice were returned to the home cage for $30 \mathrm{~min}$ before starting the next session. The protocol of test sessions was the same as for the training sessions. When they made the correct choice, mice were rewarded with a sucrose tablet in context B, except for the inference group (Figure 2) and both awake and sleep groups (Figure S3). Both the B and D contexts were square and located at the end of the arena (the same distance from the starting point) to avoid any preference that was due to geometry and distance from the starting point. Performance during the B and D test was also not due to right or left training preferences, because the design of the premise pairs was based on an equal distribution of right and left preferences (the correct choice was located to the left in two pairs and to the right in the other two pairs). After completing the inference and noninference tests, mice were tested with the original premise pairs to confirm that the performance during the inference test was due to remembering the original memories. The arena was cleaned using water and $70 \%$ ethanol after each subject. Sleep deprivation (Figure 2) was done for $4 \mathrm{~h}$ by gentle touching of the home cage after test sessions (after T1, T2, T3, and T4).

For the optogenetic inhibition experiments (Figure 3 and Figure S3), optogenetic inhibition of the ACC or PL was induced during wakefulness or sleep in a $4 \mathrm{~h}$ session. On each testing day, immediately after the test sessions, mice were anesthetized using isoflurane and two branch-type optical fibers (internal diameter, $0.25 \mathrm{~mm}$ ) were inserted and fitted into their housing with a cap, which anchored the inserted optical fibers with screws around the guide cannula. The tip of the optical fiber protruded $0.2 \mathrm{~mm}$ below the guide cannula (ACC, DV 1.2 $\mathrm{mm}$ from the skull surface; PL, DV $1.5 \mathrm{~mm}$ from the skull surface). Mice attached to the optic fibers were then placed in a sleep box and simultaneously connected to an EEG/EMG recording unit and an optical swivel wired to a laser unit $(9-12 \mathrm{~mW}, 589 \mathrm{~nm})$. The delivery of continuous light was manually controlled. After the session, mice were detached from the EEG/EMG recording and light delivery systems and the fibers were removed from the cannula under anesthesia.

For the optogenetic activation experiment (Figure 4), optogenetic activation to MEC terminals in the ACC was performed during NREM or REM sleep for two consecutive days. One day after test 1, mice were anesthetized using isoflurane and two branch-type optical fibers (internal diameter, $0.25 \mathrm{~mm}$ ) were inserted and fitted into their housing with a cap, which anchored the inserted optical fibers by screws around the guide cannula. The tip of the optical fiber protruded $0.2 \mathrm{~mm}$ below the guide cannula (DV $1.2 \mathrm{~mm}$ from the skull surface). Mice attached to the optic fibers were then placed in a sleep box, and simultaneously connected to an EEG/EMG recording unit and an optical swivel wired to a laser unit (9-12 mW, $473 \mathrm{~nm}$ ). 
The delivery of laser stimulation ( $4 \mathrm{~Hz}, 15 \mathrm{msec}$ pulse width) was manually controlled using a schedule stimulator in time-lapse mode (Master-8 pulse stimulator, A.M.P.I.). In REMstimulated mice, $4 \mathrm{~Hz}$ light stimulation was delivered during all REM sleep that occurred within the $4 \mathrm{~h}$ sleep session; the total duration of light stimulation was less than 7 min per mouse. For NREM-stimulated mice, light stimulation was delivered for a maximum of 3 min per epoch with a 3 min inter-epoch interval. After the session, the mice were detached from the EEG/EMG recording and light delivery systems and the fibers were removed from the cannula under anesthesia.

For the optogenetic activation experiment (Figure S5), the procedure was the same as that described in the previous paragraph, related to Figure 4, with a modification in the stimulation protocol; the total duration of light stimulation was modified to be less than 7 min per mouse, with a maximum of 3 min per epoch. This modification was done to avoid prolonged light stimulation and to mimic the protocol used in REM-stimulated animals.

\section{Behavioral analysis}

All sessions were captured with an overhead web camera (Logitech HD pro C920) mounted on a vertical stand. The time spent in each context during the habituation phase was counted. During training and testing, the trial was considered to be correct if mice spent $>10 \mathrm{sec}$ in the assigned context. The percent of correct trials during training and testing sessions was calculated as follows: $\%$ correct trials $=$ (number of correct trials $/$ total number of trials) $* 100$. We set $80 \%$ correct trials during the training phase as the criterion for successful learning of the premise pairs.

\section{Sleep detection data acquisition and online state detection}

All EEG/EMG recordings were performed using OpenEx Software Suite (Tucker Davis Technologies, USA), as previously described (Miyamoto et al., 2016) with minor modifications. Briefly, EEG signals were amplified and filtered at $1-40 \mathrm{~Hz}$, while $65-150 \mathrm{~Hz}$ was used for EMG; signals were then digitized at a sampling rate of $508.6 \mathrm{~Hz}$. Sleep stages were differentiated using an algorithm file that enabled the calculation and analysis of the EMG root mean square value (RMS), EEG delta power (1-4 Hz) RMS, and EEG theta power (6-9 $\mathrm{Hz}$ ) RMS. The EMG RMS threshold was optimized according to each subject. Mice was judged to be awake when the EMG RMS exceeded the set threshold value and remained unchanged for three successive 3 sec checkpoints. However, when EMG RMS was lower than the threshold, sleep stage differentiation was concluded based on the delta/theta $(d / t)$ ratio value. Briefly, if the $d / t$ ratio exceeded 1 for the consecutive 9 sec checking period, the stage was classified as NREM sleep; conversely, it was classified as REM sleep when it was less than 1 for a consecutive $9 \mathrm{sec}$. The state classified by the program was also confirmed by the experimenter through visual inspection of mouse activity and EEG delta-dominant $(0.5-4 \mathrm{~Hz})$ or theta-dominant (4-9 Hz) waveforms. EEG/EMG traces recorded during sleep sessions were then extracted using MATLAB codes.

\section{Histology}

After the optogenetic manipulation experiments, mice were deeply anesthetized with $1 \mathrm{~mL}$ of combination anesthesia and perfused transcardially with PBS (pH 7.4) followed by $4 \%$ paraformaldehyde in PBS. The brains were extracted, then further immersed in paraformaldehyde in PBS for $12-18 \mathrm{~h}$ at $4^{\circ} \mathrm{C}$. Subsequently, fixed brains were mixed with $25 \%$ sucrose in PBS for $36-48 \mathrm{~h}$ at $4^{\circ} \mathrm{C}$ before final storage at $-80^{\circ} \mathrm{C}$. To obtain coronal sections, brains were sliced into $50 \mu \mathrm{m}$ sections using a cryostat (Leica CM3050, Leica Biosystems) and were then washed in PBS-containing 12-well culture plates (Corning, NY, USA). The sections were further incubated at room temperature for $1 \mathrm{~h}$ with a blocking buffer (3\% normal donkey 
serum; S30, Chemicon by EMD Millipore, Billerica, MA, USA) in PBS solution containing $0.2 \%$ Triton X-100 and $0.05 \%$ Tween 20 (PBST). After incubation, the buffer was discarded and rat anti-GFP (04404-84, GF090R, Nacalai Tesque Inc., Japan) primary antibody (1:500) in blocking solution was added for further incubation at $4{ }^{\circ} \mathrm{C}$ for $24-36 \mathrm{~h}$. At the end of the incubation period, the primary antibody was removed and sections were washed with $0.2 \%$ PBST three times for 10 min each. After washing, sections were treated with a complementary secondary antibody, (1:1000) donkey anti-rat IgG Alexa Fluor 488 (A21208, Molecular Probes) in blocking buffer solution at room temperature for 2-3 h. Finally, the sections were treated with DAPI (1 $\mu \mathrm{g} / \mathrm{mL}$, Roche Diagnostics, 10236276001) for nuclear staining and washed with $0.2 \%$ PBST three times for 10 min each before being mounted onto glass slides with ProLong Gold antifade reagent (Invitrogen).

\section{Confocal microscopy}

Images were acquired using a confocal microscope (Zeiss LSM 780, Carl Zeiss, Jena, Germany) with 20× Plan-Apochromat objective lens. All parameters, such as the photomultiplier tube assignments, pinhole sizes, and contrast values, were standardized within each magnification and experimental condition.

\section{Statistics}

Statistical analyses were performed using Prism 8 (GraphPad Software, San Diego, CA, USA). Multiple-group comparisons were performed using an ANOVA with post hoc tests, as shown in the corresponding figure legends. Quantitative data are presented as the mean \pm SEM.

\section{SUPPLEMENTAL INFORMATION TITLES AND LEGENDS}




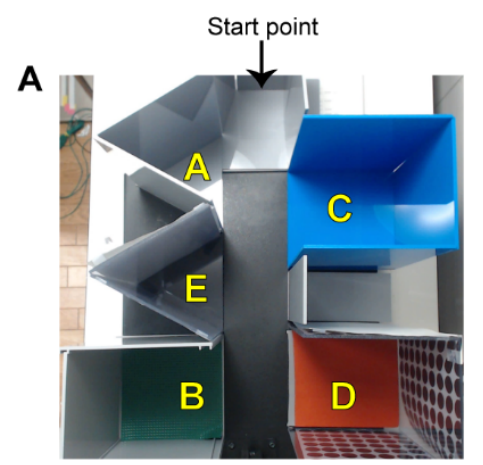

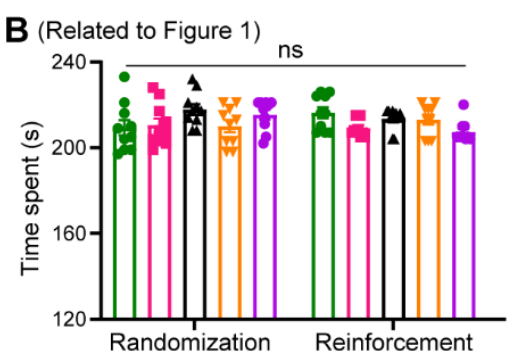

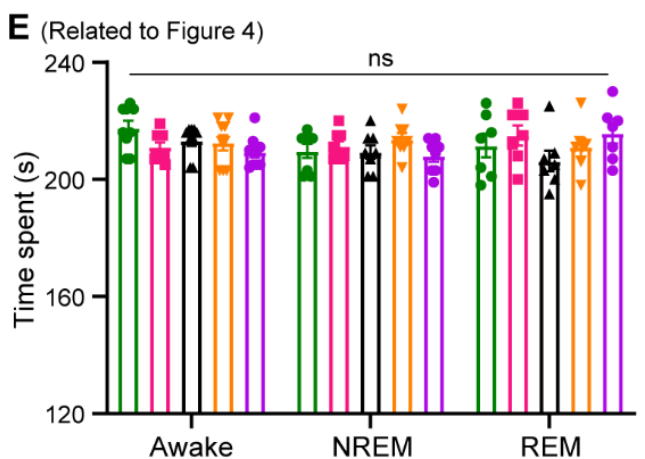

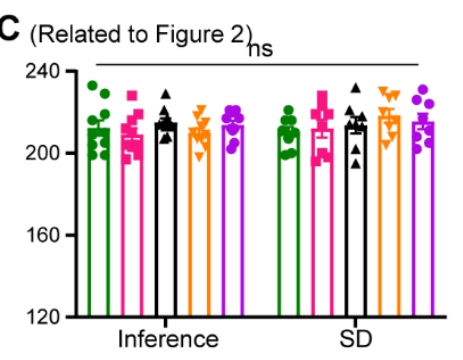

D (Related to Figure 3)

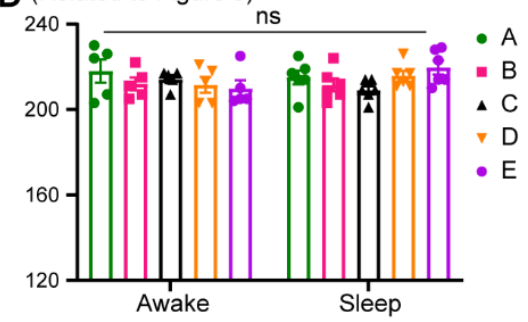

$\mathbf{F}$ (Related to Figure 5) ns

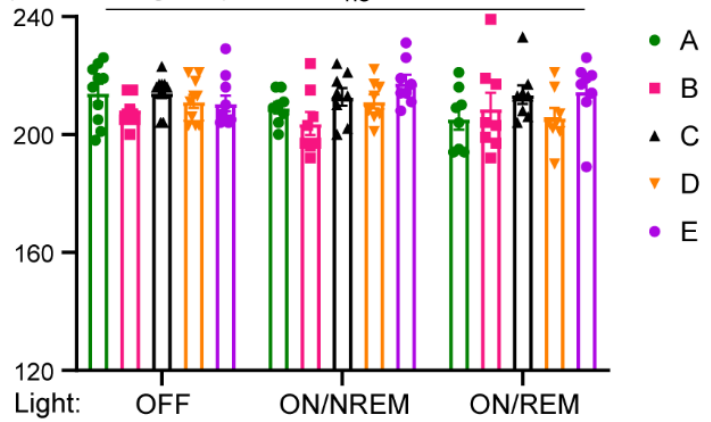

Figure S1. Mice had no innate preference to any context during habituation

(A) Representative photo of the arena and the five different contexts. The arrow represents the starting point.

(B to F) Time spent in each context during the habituation phase; mice used in Figure 1 (B), in Figure 2 (C), in Figure 3 (D), in Figure 4 (E), and in Figure 5 (F). The number of animals in each panel is mentioned in the corresponding figure legend. SD, sleep deprivation; NREM, non-rapid eye movement; REM, rapid eye movement. Statistical comparisons were made using a two-way repeated-measures analysis of variance (ANOVA) with Tukey's multiple comparison test (B to $\mathrm{F})$. ns, not significant $(\mathrm{P}>0.05)$. Data are presented as the mean \pm standard error of the mean (SEM). 


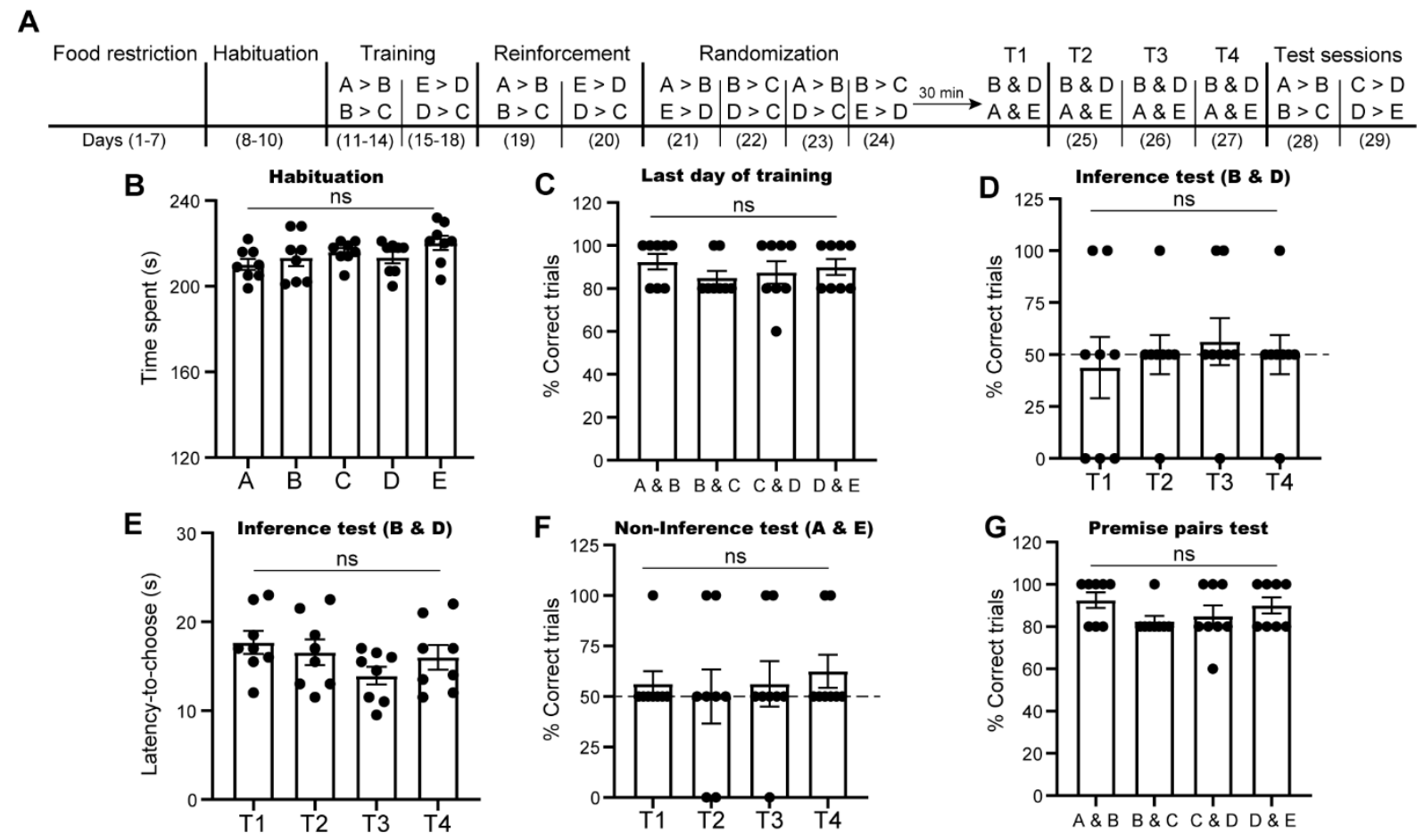

Figure S2. Organizing existing knowledge into a hierarchical order is necessary for inference

(A) The behavioral schedule used to test the impact of the complete hierarchy on inference development. The contexts' hierarchy was as follow $\mathrm{A}>\mathrm{B}>\mathrm{C}$ and $\mathrm{E}>\mathrm{D}>\mathrm{C}$.

(B) The time spent in each context during the habituation phase.

(C) The performance during the last day of training (day 14 for $\mathrm{A}>\mathrm{B}$ and $\mathrm{B}>\mathrm{C}$; day 18 for $\mathrm{E}$ $>$ D and D > C) for each premise pair was calculated as the percent of correct trials out of the total number of trials.

(D to G) Performance during test sessions; the percent of correct trials during the inference test (D), the latency time to choose during the inference test $(\mathrm{E})$, during the non-inference test $(\mathrm{F})$, during the original premise pairs test (G). T1, test 1 ; T2, test 2; T3, test 3; T4, test $4 . \mathrm{n}=8$ mice. Statistical comparisons were made using a one-way repeated-measures analysis of variance (ANOVA) with Tukey's multiple comparison test (B to G). ns, not significant (P > 0.05). Data are presented as the mean \pm standard error of the mean (SEM). 
A

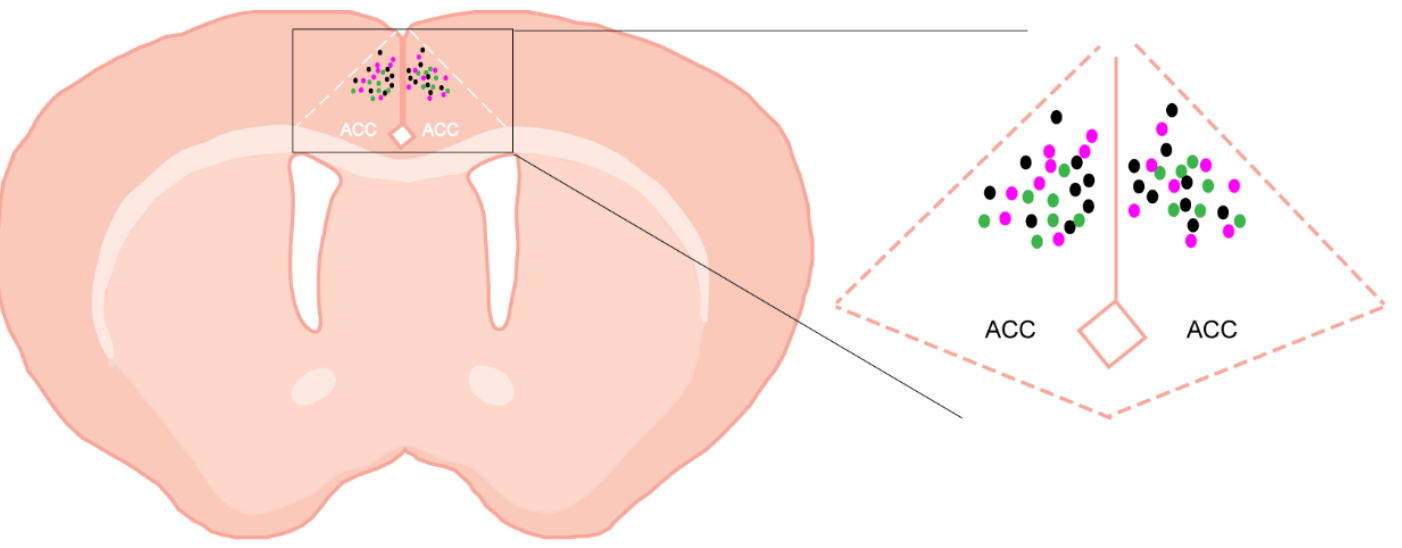

B

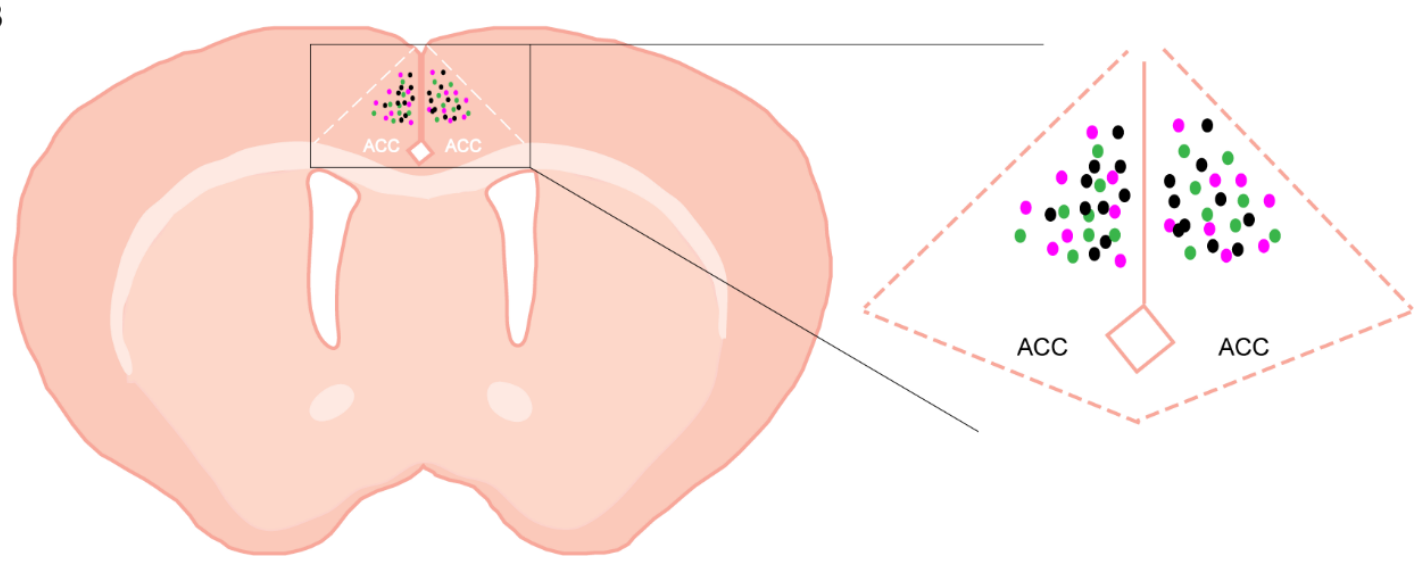

Figure S3. Optic fiber locations in mice used in the manipulation experiments

(A) Optic fiber tip location for mice shown in Figure 4. Black dots, mice in the awake group;

Green dots, mice in the NREM group; Pink dots, mice in the REM group.

(B) Optic fiber tip location for mice shown in Figure 5. Black dots, mice in the light off group; Green dots, mice in the NREM group; Pink dots, mice in the REM group. The anterior cingulate cortex (ACC) is indicated by dashed lines. 


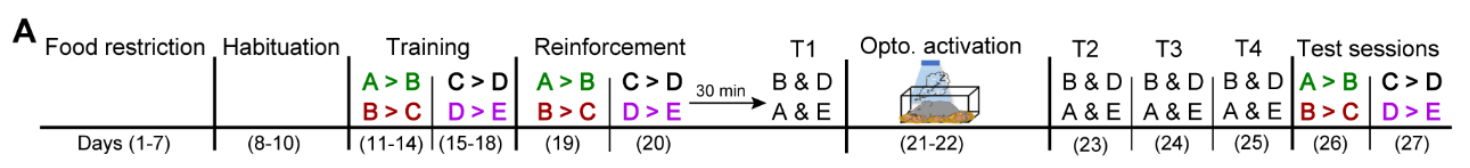

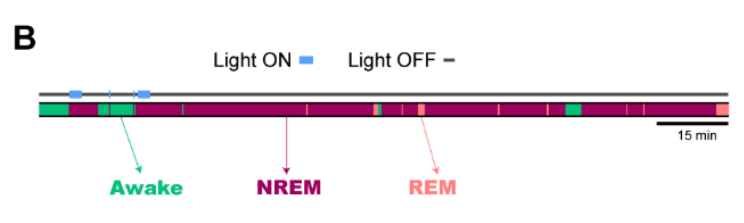
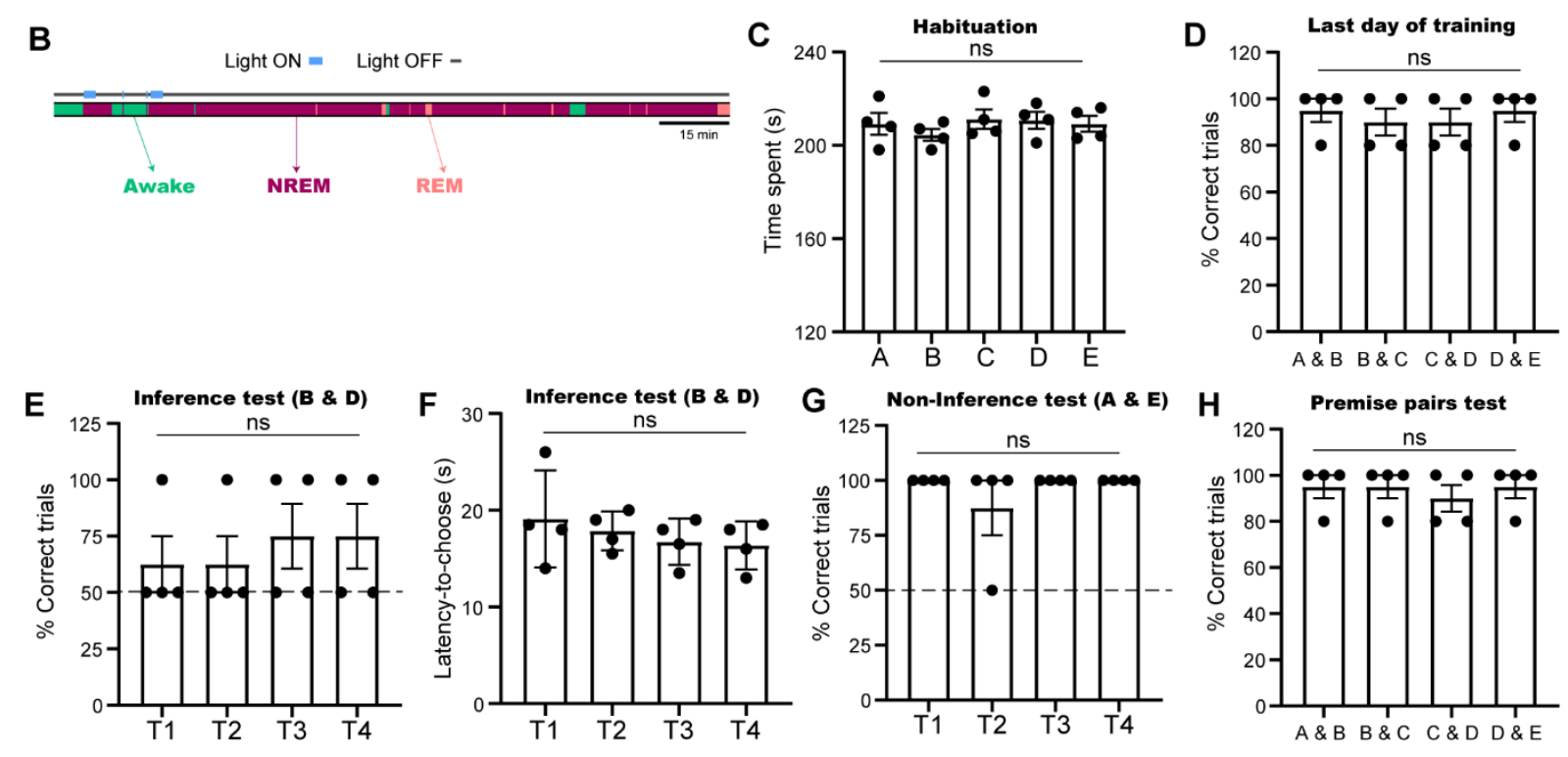

Figure S4. Optogenetic activation of $\mathrm{MEC} \rightarrow \mathrm{ACC}$ circuit during NREM sleep is not

\section{sufficient for the emergence of inference}

(A) The behavioral schedule used to manipulate $\mathrm{MEC} \rightarrow \mathrm{ACC}$ circuit activity during NREM sleep after test sessions.

(B) Diagram showing the NREM-specific manipulation. The manipulation protocol mimicked the protocol used during REM sleep in Figure 5 (see Methods). Scale bar, 15 minutes.

(C) The time spent in each context during the habituation phase.

(D) Performance during the last day of training (day 14 for A > B and B > C; day 18 for C > D and $\mathrm{D}>\mathrm{E}$ ) for each premise pair.

(E to $\mathrm{H}$ ) Performance during the test sessions; the percent of correct trials during the inference test $(\mathrm{E})$, latency time to choose during the inference test $(\mathrm{F})$, during the non-inference test $(\mathrm{G})$, during the original premise pairs test $(\mathrm{H})$. T1, test 1 ; T2, test 2 ; T3, test 3 ; T4, test $4 ; \mathrm{n}=4$ mice. Statistical comparisons were made using a one-way repeated-measures analysis of variance (ANOVA) with Tukey's multiple comparison test ( $\mathrm{C}$ to $\mathrm{H})$. ns, not significant $(\mathrm{P}>0.05)$. Data are presented as the mean \pm standard error of the mean (SEM). 


\section{References and Notes:}

ABDOU, K., SHEHATA, M., CHOKO, K., NISHIZONO, H., MATSUO, M., MURAMATSU, S. I. \& INOKUCHI, K. 2018. Synapse-specific representation of the identity of overlapping memory engrams. Science, 360, 1227-1231.

ALY, M. H., ABDOU, K., SUZUKI, R. O., NOMOTO, M., INOKUCHI, K. 2021. Offline knowledge assimilations ensue online obscurity to inspire implicit learning. bioRxiv doi: I0.1 I0I/202I.04.06.438726

BARRON, H. C., DOLAN, R. J. \& BEHRENS, T. E. 2013. Online evaluation of novel choices by simultaneous representation of multiple memories. Nat Neurosci, 16, 1492-8.

BARRON, H. C., REEVE, H. M., KOOLSCHIJN, R. S., PERESTENKO, P. V., SHPEKTOR, A., NILI, H., ROTHAERMEL, R., CAMPO-URRIZA, N., O'REILLY, J. X., BANNERMAN, D. M., BEHRENS, T. E. J. \& DUPRET, D. 2020. Neuronal Computation Underlying Inferential Reasoning in Humans and Mice. Cell, 183, 228-243 e21.

BASHEER, R., SHERIN, J. E., SAPER, C. B., MORGAN, J. I., MCCARLEY, R. W. \& SHIROMANI, P. J. 1997. Effects of sleep on wake-induced c-fos expression. J Neurosci, 17, 9746-50.

BEHRENS, T. E. J., MULLER, T. H., WHITTINGTON, J. C. R., MARK, S., BARAM, A. B., STACHENFELD, K. L. \& KURTH-NELSON, Z. 2018. What Is a Cognitive Map? Organizing Knowledge for Flexible Behavior. Neuron, 100, 490-509.

BOYCE, R., GLASGOW, S. D., WILLIAMS, S. \& ADAMANTIDIS, A. 2016. Causal evidence for the role of REM sleep theta rhythm in contextual memory consolidation. Science, 352, 812-6.

BRAMHAM, C. R. \& SREBRO, B. 1989. Synaptic plasticity in the hippocampus is modulated by behavioral state. Brain Res, 493, 74-86.

BRUNAMONTI, E., MIONE, V., DI BELLO, F., PANI, P., GENOVESIO, A. \& FERRAINA, S. 2016. Neuronal Modulation in the Prefrontal Cortex in a Transitive Inference Task: Evidence of Neuronal Correlates of Mental Schema Management. J Neurosci, 36, 1223-36.

BUCKMASTER, C. A., EICHENBAUM, H., AMARAL, D. G., SUZUKI, W. A. \& RAPP, P. R. 2004. Entorhinal cortex lesions disrupt the relational organization of memory in monkeys. $J$ Neurosci, 24, 9811-25.

CAI, D. J., MEDNICK, S. A., HARRISON, E. M., KANADY, J. C. \& MEDNICK, S. C. 2009. REM, not incubation, improves creativity by priming associative networks. Proc Natl Acad Sci U SA, 106, 10130-4.

CHEN, Z. \& WILSON, M. A. 2017. Deciphering Neural Codes of Memory during Sleep. Trends Neurosci, 40, 260-275.

CIRELLI, C. \& TONONI, G. 2000a. Differential expression of plasticity-related genes in waking and sleep and their regulation by the noradrenergic system. J Neurosci, 20, 9187-94.

CIRELLI, C. \& TONONI, G. 2000b. Gene expression in the brain across the sleep-waking cycle. Brain Res, 885, 303-21.

COUSINS, J. N., EL-DEREDY, W., PARKES, L. M., HENNIES, N. \& LEWIS, P. A. 2014. Cued memory reactivation during slow-wave sleep promotes explicit knowledge of a motor sequence. $J$ Neurosci, 34, 15870-6.

DUSEK, J. A. \& EICHENBAUM, H. 1997. The hippocampus and memory for orderly stimulus relations. Proc Natl Acad Sci U S A, 94, 7109-14.

ELLENBOGEN, J. M., HU, P. T., PAYNE, J. D., TITONE, D. \& WALKER, M. P. 2007. Human relational memory requires time and sleep. Proc Natl Acad Sci U S A, 104, 7723-8.

GAIS, S. \& BORN, J. 2004. Low acetylcholine during slow-wave sleep is critical for declarative memory consolidation. Proc Natl Acad Sci U S A, 101, 2140-4.

GHANDOUR, K., OHKAWA, N., FUNG, C. C. A., ASAI, H., SAITOH, Y., TAKEKAWA, T., OKUBO-SUZUKI, R., SOYA, S., NISHIZONO, H., MATSUO, M., OSANAI, M., SATO, M., OHKURA, M., NAKAI, J., 
HAYASHI, Y., SAKURAI, T., KITAMURA, T., FUKAI, T. \& INOKUCHI, K. 2019. Orchestrated ensemble activities constitute a hippocampal memory engram. Nat Commun, 10, 2637.

GIRARDEAU, G., BENCHENANE, K., WIENER, S. I., BUZSAKI, G. \& ZUGARO, M. B. 2009. Selective suppression of hippocampal ripples impairs spatial memory. Nat Neurosci, 12, 1222-3.

GRIDCHYN, I., SCHOENENBERGER, P., O'NEILL, J. \& CSICSVARI, J. 2020. Assembly-Specific Disruption of Hippocampal Replay Leads to Selective Memory Deficit. Neuron, 106, 291-300 e6.

GUPTA, A. S., VAN DER MEER, M. A., TOURETZKY, D. S. \& REDISH, A. D. 2010. Hippocampal replay is not a simple function of experience. Neuron, 65, 695-705.

IIDA, A., TAKINO, N., MIYAUCHI, H., SHIMAZAKI, K. \& MURAMATSU, S. 2013. Systemic delivery of tyrosine-mutant AAV vectors results in robust transduction of neurons in adult mice. Biomed Res Int, 2013, 974819.

KONNO, A. \& HIRAI, H. 2020. Efficient whole brain transduction by systemic infusion of minimally purified AAV-PHP.eB. J Neurosci Methods, 346, 108914.

LEWIS, P. A., KNOBLICH, G. \& POE, G. 2018. How Memory Replay in Sleep Boosts Creative ProblemSolving. Trends Cogn Sci, 22, 491-503.

LI, X. G., OKADA, T., KODERA, M., NARA, Y., TAKINO, N., MURAMATSU, C., IKEGUCHI, K., URANO, F., ICHINOSE, H., METZGER, D., CHAMBON, P., NAKANO, I., OZAWA, K. \& MURAMATSU, S. 2006. Viral-mediated temporally controlled dopamine production in a rat model of Parkinson disease. Mol Ther, 13, 160-6.

LIU, Y., DOLAN, R. J., KURTH-NELSON, Z. \& BEHRENS, T. E. J. 2019. Human Replay Spontaneously Reorganizes Experience. Cell, 178, 640-652 e14.

MIYAMOTO, D., HIRAI, D., FUNG, C. C., INUTSUKA, A., ODAGAWA, M., SUZUKI, T., BOEHRINGER, R., ADAIKKAN, C., MATSUBARA, C., MATSUKI, N., FUKAI, T., MCHUGH, T. J., YAMANAKA, A. \& MURAYAMA, M. 2016. Top-down cortical input during NREM sleep consolidates perceptual memory. Science, 352, 1315-8.

OLAFSDOTTIR, H. F., BARRY, C., SALEEM, A. B., HASSABIS, D. \& SPIERS, H. J. 2015. Hippocampal place cells construct reward related sequences through unexplored space. Elife, 4, e06063.

OLAFSDOTTIR, H. F., BUSH, D. \& BARRY, C. 2018. The Role of Hippocampal Replay in Memory and Planning. Curr Biol, 28, R37-R50.

PENAGOS, H., VARELA, C. \& WILSON, M. A. 2017. Oscillations, neural computations and learning during wake and sleep. Curr Opin Neurobiol, 44, 193-201.

PLIHAL, W. \& BORN, J. 1997. Effects of early and late nocturnal sleep on declarative and procedural memory. J Cogn Neurosci, 9, 534-47.

PLIHAL, W. \& BORN, J. 1999. Memory consolidation in human sleep depends on inhibition of glucocorticoid release. Neuroreport, 10, 2741-7.

POE, G. R., WALSH, C. M. \& BJORNESS, T. E. 2010. Cognitive neuroscience of sleep. Prog Brain Res, 185, 1-19.

POMPEIANO, M., CIRELLI, C., ARRIGHI, P. \& TONONI, G. 1995. c-Fos expression during wakefulness and sleep. Neurophysiol Clin, 25, 329-41.

POMPEIANO, M., CIRELLI, C., RONCA-TESTONI, S. \& TONONI, G. 1997. NGFI-A expression in the rat brain after sleep deprivation. Brain Res Mol Brain Res, 46, 143-53.

POMPEIANO, M., CIRELLI, C. \& TONONI, G. 1994. Immediate-early genes in spontaneous wakefulness and sleep: expression of c-fos and NGFI-A mRNA and protein. J Sleep Res, 3, 80-96.

PRESTON, A. R. \& EICHENBAUM, H. 2013. Interplay of hippocampus and prefrontal cortex in memory. Curr Biol, 23, R764-73.

RIBEIRO, S., GOYAL, V., MELLO, C. V. \& PAVLIDES, C. 1999. Brain gene expression during REM sleep depends on prior waking experience. Learn Mem, 6, 500-8.

RIBEIRO, S., MELLO, C. V., VELHO, T., GARDNER, T. J., JARVIS, E. D. \& PAVLIDES, C. 2002. Induction of hippocampal long-term potentiation during waking leads to increased extrahippocampal zif268 expression during ensuing rapid-eye-movement sleep. J Neurosci, 22, 10914-23. 
SPALDING, K. N., SCHLICHTING, M. L., ZEITHAMOVA, D., PRESTON, A. R., TRANEL, D., DUFF, M. C. \& WARREN, D. E. 2018. Ventromedial Prefrontal Cortex Is Necessary for Normal Associative Inference and Memory Integration. J Neurosci, 38, 3767-3775.

STICKGOLD, R. \& WALKER, M. P. 2013. Sleep-dependent memory triage: evolving generalization through selective processing. Nat Neurosci, 16, 139-45.

WAGNER, U., GAIS, S., HAIDER, H., VERLEGER, R. \& BORN, J. 2004. Sleep inspires insight. Nature, 427, 352-5.

WALKER, M. P. 2009. The role of sleep in cognition and emotion. Ann N Y Acad Sci, 1156, 168-97.

WALKER, M. P., LISTON, C., HOBSON, J. A. \& STICKGOLD, R. 2002. Cognitive flexibility across the sleep-wake cycle: REM-sleep enhancement of anagram problem solving. Brain Res Cogn Brain Res, 14, 317-24.

WAMSLEY, E. J., TUCKER, M., PAYNE, J. D., BENAVIDES, J. A. \& STICKGOLD, R. 2010. Dreaming of a learning task is associated with enhanced sleep-dependent memory consolidation. Curr Biol, 20, 850-5.

WILSON, M. A. \& MCNAUGHTON, B. L. 1994. Reactivation of hippocampal ensemble memories during sleep. Science, 265, 676-9.

WONG, F. S., WESTBROOK, R. F. \& HOLMES, N. M. 2019. 'Online' integration of sensory and fear memories in the rat medial temporal lobe. Elife, 8.

YOKOSE, J., OKUBO-SUZUKI, R., NOMOTO, M., OHKAWA, N., NISHIZONO, H., SUZUKI, A., MATSUO, M., TSUJIMURA, S., TAKAHASHI, Y., NAGASE, M., WATABE, A. M., SASAHARA, M., KATO, F. \& INOKUCHI, K. 2017. Overlapping memory trace indispensable for linking, but not recalling, individual memories. Science, 355, 398-403.

ZEITHAMOVA, D., DOMINICK, A. L. \& PRESTON, A. R. 2012. Hippocampal and ventral medial prefrontal activation during retrieval-mediated learning supports novel inference. Neuron, $75,168-79$. 